University of Wollongong

Research Online

Faculty of Engineering and Information

Faculty of Engineering and Information

Sciences - Papers: Part A

Sciences

$1-1-2015$

Optimal distribution control of non-linear tire force of electric vehicles with in-wheel motors

Boyuan $\mathrm{Li}$

University of Wollongong, bl995@uowmail.edu.au

Haiping Du

University of Wollongong, hdu@uow.edu.au

Weihua Li

University of Wollongong, weihuali@uow.edu.au

Follow this and additional works at: https://ro.uow.edu.au/eispapers

Part of the Engineering Commons, and the Science and Technology Studies Commons

Research Online is the open access institutional repository for the University of Wollongong. For further information contact the UOW Library: research-pubs@uow.edu.au 


\title{
Optimal distribution control of non-linear tire force of electric vehicles with in-wheel motors
}

\author{
Abstract \\ An over-actuated control system has the advantage of being able to use redundant actuators to \\ reconfigure the control system and it can realize fault tolerant control. In order to achieve improved \\ vehicle stability and handling performance for electric vehicles with in-wheel steering and driving motors, \\ the control of the vehicle body slip angle and yaw rate is actually an over-actuated control problem. To \\ obtain the optimal solution for this control problem, this study proposes a two-level tire force distribution \\ control method, where the upper level controller calculates the desired lateral and longitudinal forces \\ generated by friction on the tire of each wheel according to the driver's steering and driving inputs. The \\ lower level controller maps the desired tire forces into the input of each steering actuator and driving \\ actuator. Unlike the linear mapping method applied in most of the current research, this study develops a \\ proportional-integral $(\mathrm{PI})$ controller for each actuator so that the nonlinear tire characteristics can be \\ counteracted. In addition, since the PI controllers for eight actuators (four steering actuators and four \\ driving actuators) have a total of 16 control gains to be determined, a genetic algorithm is applied to \\ accurately determine these control gains. The simulation results are presented to validate the control \\ performance of the proposed tire force allocation method.
}

\section{Keywords}

wheel, motors, vehicles, optimal, electric, force, tire, linear, non, control, distribution

\author{
Disciplines \\ Engineering | Science and Technology Studies
}

\section{Publication Details}

B. Li, H. Du \& W. Li, "Optimal distribution control of non-linear tire force of electric vehicles with in-wheel motors," Asian Journal of Control, vol. 18, (1) pp. 69-88, 2016. 


\title{
Optimal distribution control of the non-linear tyre force of electric vehicles with in-wheel motors
}

\author{
Boyuan $\mathrm{Li}^{1}$, Haiping $\mathrm{Du}^{1}$ and Weihua $\mathrm{Li}^{2}$ \\ 1. School of Electrical, Computer and Telecommunications Engineering, University of Wollongong, \\ Wollongong, NSW 2522, Australia
}

2. School of Mechanical, Material and Mechatronic Engineering, University of Wollongong,

Wollongong, NSW 2522, Australia

\begin{abstract}
:
An over-actuated control system has the advantage that it can use redundant actuators to reconfigure the control system and can realise fault tolerant control. In order to achieve improved vehicle stability and handling performance for electric vehicles with in-wheel steering and driving motors, the control of the vehicle body slip angle and yaw rate is actually an over-actuated control problem. To obtain the optimal solution for this control problem, this study proposes a two-level tyre force distribution control method, where the upper level controller calculates the desired lateral and longitudinal forces generated by friction on the tyre of each wheel according to the driver's steering and driving inputs. The lower level controller maps the desired tyre forces into the input of each steering actuator and driving actuator. Unlike the linear mapping method applied in most of the current research, this study develops a proportional-integral (PI) controller for each actuator so that the non-linear tyre characteristics can be counteracted. In addition, since the PI controllers for eight actuators (four steering actuators and four driving actuators) have a total of 16 control gains to be determined, a genetic algorithm is applied to accurately determine these control gains. The simulation results are presented to validate the control performance of the proposed tyre force allocation method.
\end{abstract}

Key words: yaw rate control, side slip angle control, optimal control allocation method, genetic algorithm, electric vehicle, in-wheel motors

\section{INTRODUCTION}

In an over-actuated control system, the number of actuators is greater than the controlled degree of freedom or the number of desired control targets.

Johansen and Fossen [1] suggest that over-actuated systems are preferable because: 
- The actuator redundancy can meet the requirements of fault tolerance and control reconfiguration.

- Because of their cost, accuracy and dynamic response, a larger set of actuators can be used.

- The actuators can be shared among several control systems with different objectives.

These advantages have led to much recent research in the area of control allocation (CA). CA was firstly applied in the areas of aerospace and marine engineering. Oppenheimer et al. focused on the aerospace application of CA [2] while Fossen and Johansen proposed it for marine application. [3] Numerical computation-based CA, which uses various quadratic/nonlinear programming algorithms and incorporates the terms which indicate the resulting negative effects in the cost function, shows the advantage of fully utilised redundant actuators and plays an important role in over-actuated systems. [4][5] In recent years, there has been an increasing interest in applying CA in the automotive industry. For electric vehicles with inwheel steering and driving motors, the control of the vehicle body slip angle and yaw rate is actually an over-actuated control problem. In [6] and [7], a lateral motion controller for four wheel drive (4WD) and front wheel steering electric vehicles was proposed and the combined active front wheel steering and direct yaw moment control through in-vehicle networks with real-time message priority scheduling was applied in the controller. To realise the desired control target, the optimal torque allocation algorithm using the quadratic form as the cost function was adopted in [6]. This algorithm can be solved as a quadratic programming (QP) problem with constraints, but solving a large number of non-linear optimization problems at each time step is problematic due to the high computational cost. [8] To save computational time, Gerard et al. used a virtual control law determined offline to implement the CA method. [9] This study suggested that this virtual control law did not need to be explicitly solved at each time step, but trended in an optimal direction for a convex optimization problem. The adaptive CA method was also proposed to save computational time, since the CA problem can be solved dynamically without the necessity of finding the optimal solution at each sampling instant. Tjønnås and Johanson developed the adaptive CA method so that it could asymptotically achieve the optimal control. [10] The energy-efficient control allocation (EECA) method was designed for the longitudinal speed tracking control of an electric vehicle with two pairs of in-wheel driving motors in [11], where three different EECA methods, i.e., adaptive-EECA, Karush-Kuhn-Tucker (KKT)-based EECA and rule-based EECA were presented. Demirci and Gokasan also developed the adaptive stability control of a four-wheel steering (4WS)-4WD electric vehicle [12]. In Demirci and Gokasan's paper, a Lagrangian neural network approach was suggested to solve the non-linear optimization problem using an adaptive control method, which obviated the necessity of solving the optimization problem explicitly in every time step. The main problem of the abovementioned methods is that they need to solve a very complex optimization problem. Ando and Fujimoto, instead, used a linear longitudinal and lateral tyre force distribution method for the direct yaw-moment controller, and the optimal value can be solved by the linear equation at every time step [13]. Suzuki et al. also proposed tyre-force distribution control for a full drive-by-wire electric vehicle. [14] The control target is to minimize the tyre workload and dissipation energy due to tyre slip. Based on the defined control targets, the desired total 
longitudinal tyre force, total lateral tyre force and yaw moment can be achieved by appropriately distributing the individual tyre force of each wheel. However, the above two studies have the disadvantage of the linear mapping of the distributed tyre forces to the distributed steering actuators or traction/brake torque actuators, and this is not accurate because of the non-linear characteristics of the tyre.

In this study, the desired control targets of body slip angle and yaw rate are achieved not only by appropriately distributing individual tyre force, but also by controlling the individual tyre slip ratio and slip angle through proportional-integral (PI) controllers. This means that the steering actuators and traction/brake actuators can be controlled in order to achieve the desired tyre slip ratio and slip angle. These desired values are calculated from the desired tyre force and non-linear Dugoff tyre model because they can accurately represent the non-linear tyre characteristics. It should be noted that each PI controller in the individual wheel has 4 control gains to determine ( 2 for the traction/brake torque and 2 for the steering angle), while the whole system has 16 control gains to determine. These control gains are difficult to tune using trial-and-error and consequently the genetic algorithm (GA) is proposed here to determine these control gains as accurately as possible.

GA originated from the computer science field of artificial intelligence, which is a type of search heuristics which mimics the process of natural selection. In recent years, GA was used for an unrelated parallel machine scheduling problem in the operational research area. [15] A hybrid GA with adaptive diversity management was proposed for the routing problem of a large class of vehicles. [16] The parallel GA and particle swarm optimization were compared for the path planning of the autonomous unmanned aerial vehicles. [17] To the best of our knowledge, however, to date there have been no studies on applying the GA to vehicle dynamics actuator optimal distribution control.

This paper is organized as follows. First, the vehicle dynamics model of a 4WS/4WD electric vehicle is introduced. Then the non-linear tyre force optimal distribution control method is introduced. Finally, simulation examples are used to validate the effectiveness of the proposed control method.

\section{VEHICLE DYNAMICS MODEL}

\subsection{Vehicle dynamics model}

In this paper, a 4WS/4WD vehicle model as shown in Figure 1 is utilised to describe the dynamics motion of the electric vehicle with in-wheel steering and driving motors. [18][19] This model is regarded as a real vehicle, and is used to validate the performance of the proposed tyre force control distribution method. 


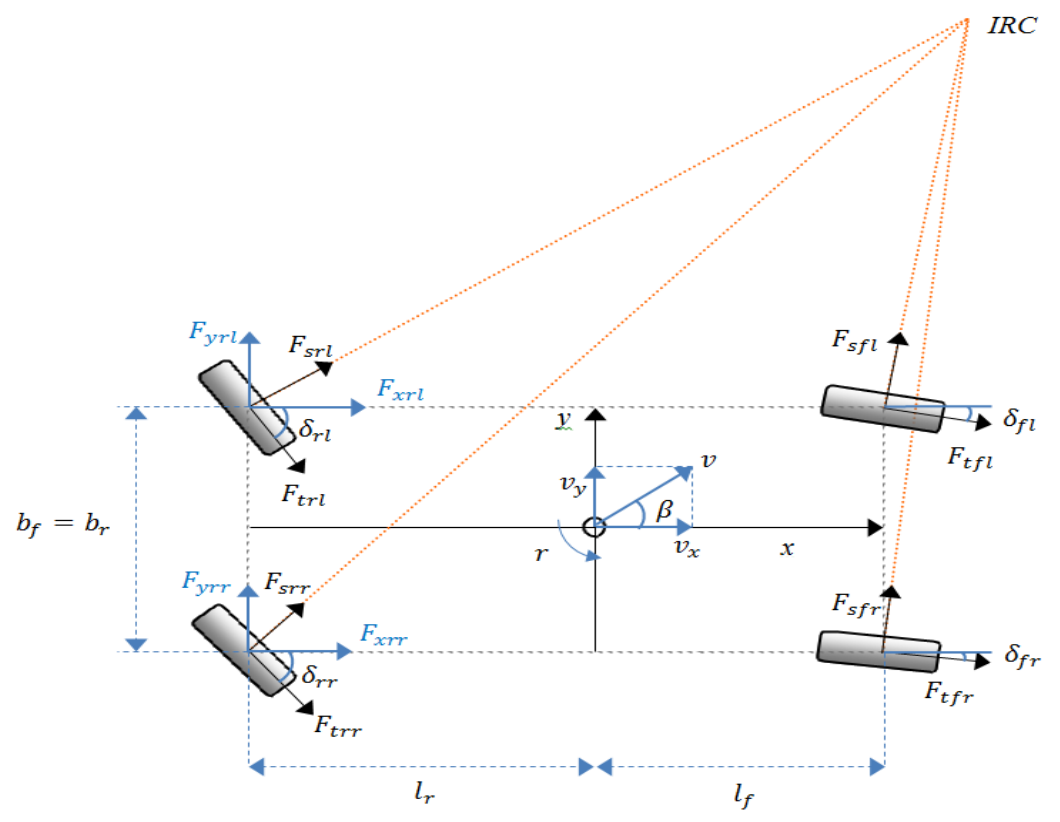

Figure 1. 4WS-4WD vehicle dynamics model, where $I R C$ represents the instantaneous centre of rotation.

The equations of motion of this model are described as follows:

Longitudinal motion:

$$
m \dot{v}_{x}=m v_{y} r+\left(F_{x f l}+F_{x f r}+F_{x r l}+F_{x r r}\right)
$$

Lateral motion:

$$
m \dot{v}_{y}=-m v_{x} r+\left(F_{y f l}+F_{y f r}+F_{y r l}+F_{y r r}\right)
$$

Yaw motion:

$$
I_{z} \dot{r}=l_{f}\left(F_{y f l}+F_{y f r}\right)-l_{r}\left(F_{y r l}+F_{y r r}\right)+\frac{b_{f}}{2}\left(F_{x f l}-F_{x f r}\right)+\frac{b_{r}}{2}\left(F_{x r l}-F_{x r r}\right)
$$

where $v_{x}, v_{y}, r$ are the vehicle longitudinal velocity, lateral velocity, and yaw rate, respectively. $F_{x f l}, F_{x f r}, F_{x r l}, F_{x r r}$ are the vehicle front left, front right, rear left and rear right longitudinal tyre forces, respectively, and $F_{y f l}, F_{y f r}, F_{y r l}, F_{y r r}$ are the vehicle front left, front right, rear left and rear right lateral tyre forces, respectively. $l_{f}$ and $l_{r}$ are the front and rear 
wheel base lengths, while $b_{f}$ and $b_{r}$ are the front and rear track widths. $I_{z}$ and $m$ are the moment of vehicle inertia in terms of yaw axis and vehicle mass.

The tyre traction or brake force and side force are defined as $F_{t i}$ and $F_{s i}$, respectively, which can be related to the longitudinal and the lateral tyre forces by the steering angle $\delta_{i}$ as follows:

$$
\begin{aligned}
& F_{x i}=F_{t i} \cos \delta_{i}-F_{s i} \sin \delta_{i} \\
& F_{y i}=F_{t i} \sin \delta_{i}+F_{s i} \cos \delta_{i}
\end{aligned}
$$

where $i=f l, f r, r l, r r$, which represents the front left, front right, rear left and rear right wheel, respectively.

\subsection{Vehicle tyre model}

The non-linear Dugoff tyre model is used in this paper [20], and is described by:

$$
\begin{gathered}
\lambda_{i}=\frac{\mu F_{z i}\left[1-\varepsilon_{r} u_{i} \sqrt{s_{i}^{2}+\tan ^{2} \alpha_{i}}\right]\left(1-s_{i}\right)}{2 \sqrt{C_{s}^{2} s_{i}^{2}+C_{\alpha}^{2} \tan ^{2} \alpha_{i}}} \\
f\left(\lambda_{i}\right)= \begin{cases}\lambda_{i}\left(2-\lambda_{i}\right) & \left(\lambda_{i}<1\right) \\
1 & \left(\lambda_{i}>1\right)\end{cases} \\
F_{s i}=\frac{C_{\alpha} \tan \alpha_{i}}{1-s_{i}} f\left(\lambda_{i}\right) \\
F_{t i}=\frac{C_{s} s_{i}}{1-s_{i}} f\left(\lambda_{i}\right)
\end{gathered}
$$

where $\mu$ is the tyre-road friction coefficient. $F_{z i}$ is the vertical load of each wheel. $C_{s}$ is the longitudinal cornering stiffness and $C_{\alpha}$ is the lateral cornering stiffness. $s_{i}$ is the longitudinal slip ratio, and $\alpha_{i}$ is the lateral slip angle. $\varepsilon_{r}$ is a constant value, and $u_{i}$ is the vehicle velocity component in the wheel plane which is defined for each wheel as:

$$
\begin{aligned}
& u_{f l}=\left(v_{x}+\frac{1}{2} b_{f} r\right) \cos \delta_{f l}+\left(v_{y}+l_{f} r\right) \sin \delta_{f l} \\
& u_{f r}=\left(v_{x}-\frac{1}{2} b_{f} r\right) \cos \delta_{f r}+\left(v_{y}+l_{f} r\right) \sin \delta_{f r} \\
& u_{r l}=\left(v_{x}+\frac{1}{2} b_{r} r\right) \cos \delta_{r l}-\left(l_{r} r-v_{y}\right) \sin \delta_{r l}
\end{aligned}
$$




$$
u_{r l}=\left(v_{x}-\frac{1}{2} b_{r} r\right) \cos \delta_{r r}-\left(l_{r} r-v_{y}\right) \sin \delta_{r r}
$$

\section{NON-LiNEAR TyRe ForCE OPTIMAL DistribUtion CONTROL METHOD}

To improve vehicle yaw stability and handling performance, two control objectives, i.e., keeping desired vehicle body slip angle and keeping desired yaw rate, will be targeted. As there are more control inputs than control objectives for a 4WS/4WD electric vehicle, it is an over-actuated control system and an allocation method needs to be applied. In this study, a two-level control allocation method [14] is proposed. According to the desired control targets, the upper level controller is used to determine the ideal distributed tyre force for each wheel and the lower level controller aims to map the desired tyre force of each wheel to the control command of each driving or steering actuator. Figure 2 shows the block diagram of the whole tyre force optimal distribution control system.

For traditional vehicles, the driver's steering input is directly connected to the steering wheel, while the driver's acceleration pedal is linked to the throttle of the engine and the brake pedal is connected to the brake system. For electric vehicles with in-wheel motors, a new control system can be designed so that the driver is only required to determine the virtual input steering angle, and traction or braking torque, and the control allocation method can automatically control the individual actuators based on the virtual control inputs. The control system can guarantee the stability and handling of the vehicle. This can significantly decrease the driver's workload and the vehicle dynamics performance can be improved by this automatic control system.

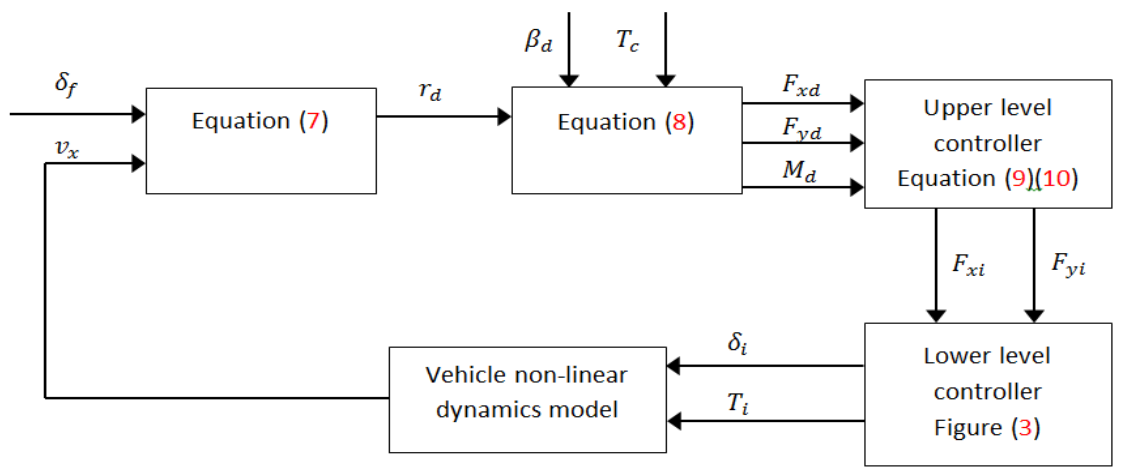

Figure 2. Block diagram of the control allocation system. 


\subsection{Design of tyre longitudinal force and lateral force controller in the upper level}

In the upper level, a tyre force controller is designed to obtain the optimal longitudinal and lateral forces for each wheel according to the desired vehicle yaw rate and body side-slip angle. In addition, in order to avoid severe loading on an individual tyre during vehicle motion, the workload of each individual wheel must be minimised.

The yaw rate control aims to improve vehicle handling. The desired yaw rate $r_{d}$ can be calculated by [19]:

$$
r_{d}=\frac{v_{x} \delta_{f}}{\left(l_{f}+l_{r}\right)\left(1+A v_{x}^{2}\right)}
$$

where $A=-\frac{m}{2\left(l_{f}+l_{r}\right)^{2}} \frac{C_{\alpha f}\left(l_{f}-l_{r}\right)}{C_{a f} C_{a r}}$ is defined as the stability factor. $C_{\alpha f}$ and $C_{\alpha r}$ are the front tyre and rear tyre cornering stiffness, which are assumed to be the same value as $C_{\alpha}$ in this research. It should be noted that the tyre cornering stiffness is an inherent property of the tyre and has been determined by various experimental tests. The corner stiffness value used in this study is based on a group of simulation parameters which has been tested and shown to be accurate [19]. Usually, the vehicle has four of the same type tyres so the cornering stiffness of each tyre is the same. [19][21][22] $v_{x}$ is the vehicle longitudinal velocity, which, here, we assume to be known.

Body slip angle control can improve vehicle stability and the desired body slip angle is zero $\left(\beta_{d}=0\right)$ [19][23]. The desired total longitudinal force $F_{x d}$, total lateral force $F_{y d}$ and yaw moment $M_{d}$ can be determined based on the desired yaw rate and body slip angle as:

$$
\begin{gathered}
M_{d}=I_{z} \dot{r}_{d} \\
F_{y d}=m v_{x}\left(\dot{\beta}_{d}+r_{d}\right)=m v_{x} r_{d} \\
F_{x d}=\frac{T_{c}}{R_{w}}
\end{gathered}
$$

where $T_{C}$ is the driving input from the driver. In $(8 \mathrm{~b})$, the total desired lateral tyre force $F_{y d}$ is determined by $m v_{x}\left(\dot{\beta}_{d}+r_{d}\right)$ [14]. We have assumed that the desired body slip angle $\beta_{d}$ is equal to zero and consequently the derivative of the desired body slip angle $\dot{\beta}_{d}$ also equals zero. Thus, $F_{y d}$ is determined by $m v_{x} r_{d}$. In this system, the driver is only required to determine the virtual input steering angle $\delta_{f}$ and the virtual driving torque $T_{c}$. Then the upper level control system will automatically calculate the desired yaw rate and body slip angle, and consequently the desired total longitudinal force, total lateral force and total yaw moment can be determined.

It should be noted that if the driver wants to maintain a constant velocity when turning, the desired total longitudinal force $F_{x d}$ must be zero and the longitudinal vehicle velocity $v_{x}$ in 
equations (7) and (8) is the constant value of the initial velocity. This is because when the vehicle is turning at a constant velocity, the motion is a uniform circular motion. The longitudinal acceleration is zero, and the lateral acceleration is the centripetal acceleration in the uniform circular motion. Accordingly, the total longitudinal force $F_{x d}$ should be zero, and the total lateral tyre force $F_{y d}$ provides the centripetal force. This means the control system will automatically adjust the driving actuators to maintain zero total longitudinal tyre force when turning.

In summary, the cost function of the upper level controller is defined as:

$$
\begin{gathered}
J_{1}=\frac{a}{2} \sum_{i=1}^{4} \frac{F_{x i}^{2}+F_{y i}^{2}}{F_{z i}^{2}}+\frac{b}{2}\left(F_{x d}-\left(F_{x f l}+F_{x f r}+F_{x r l}+F_{x r r}\right)\right)^{2} \\
+\frac{c}{2}\left(F_{y d}-\left(F_{y f l}+F_{y f r}+F_{y r l}+F_{y r r}\right)\right)^{2}+ \\
\frac{d}{2}\left(M_{d}-\left(l_{f}\left(F_{y f l}+F_{y f r}\right)-l_{r}\left(F_{y r l}+F_{y r r}\right)+\frac{b_{f}}{2}\left(F_{x f l}-F_{x f r}\right)+\frac{b_{r}}{2}\left(F_{x r l}-F_{x r r}\right)\right)\right)^{2}
\end{gathered}
$$

where $a, b, c$ and $d$ are four scaling factors which determine the weight of each term. The range of each scaling factor is between 0 and 1 . The larger the value of the scaling factor, the greater the weight of the corresponding term in the cost function. In the default setting, all the scaling factors are assumed to be 1 , since the four terms are assumed to have equal priority, and each value of the scaling factor can be decreased so that the corresponding term has less weight. When $F_{x d}, F_{y d}$ and $M_{d}$ are determined, the objective cost function (9) has eight variables $\left(F_{x i}\right.$ and $\left.F_{y i}\right)$. The minimised value can be obtained by calculating the partial differential of the objective function as:

$$
\frac{\partial J_{1}}{\partial F_{x f l}}=0, \frac{\partial J_{1}}{\partial F_{x f r}}=0, \frac{\partial J_{1}}{\partial F_{x r l}}=0, \frac{\partial J_{1}}{\partial F_{x r r}}=0, \frac{\partial J_{1}}{\partial F_{y f l}}=0, \frac{\partial J_{1}}{\partial F_{y f r}}=0, \frac{\partial J_{1}}{\partial F_{y r l}}=0, \frac{\partial J_{1}}{\partial F_{y r r}}=0
$$

Equation (10) calculates the optimal distributed tyre forces along the $\mathrm{x}$ and the $\mathrm{y}$-axes.

\subsection{Design of tyre longitudinal slip ratio and lateral slip angle controllers in the lower level}

In the upper level, the desired tyre forces are obtained according to the driver's virtual steering input $\delta_{f}$ and virtual driving input $T_{c}$. When the desired longitudinal and lateral tyre forces are determined, the next problem is how to most accurately map the desired tyre forces into the actual inputs of the steering angle and driving torque of each actuator. It should be noted that the driver cannot directly control the individual steering and driving actuators of each wheel in this study and these actual steering and driving actuators are controlled by the proposed two-level distribution control system. 
Before mapping the tyre forces into the command of each individual actuator, the tyre forces must be mapped into the directions along the tyre (traction or brake force $F_{t i}$ ) and perpendicular to the tyre (side force $F_{s i}$ ) according to equation (4) as:

$$
\begin{gathered}
F_{t i}=\frac{F_{x i}+F_{y i}}{\left(1+\tan \delta_{i}\right) \cos \delta_{i}} \\
F_{s i}=\frac{F_{y i}-F_{x i} \tan \delta_{i}}{\sin \delta_{i}+\frac{\tan \delta_{i}}{\cos \delta_{i}}}
\end{gathered}
$$

Suzuki et al. used the simple linear relations between the steering angle, driving torque and side force $F_{s i}$ or traction or brake force $F_{t i}$ as shown in equations (12) and (13). [14]

$$
\begin{gathered}
F_{s f l}=-C_{a}\left(\beta+\frac{l_{f} r}{v_{x}}-\delta_{f l}\right) \\
F_{s f r}=-C_{a}\left(\beta+\frac{l_{f} r}{v_{x}}-\delta_{f r}\right) \\
F_{s r l}=-C_{a}\left(\beta-\frac{l_{r} r}{v_{x}}-\delta_{r l}\right) \\
F_{s r r}=-C_{a}\left(\beta-\frac{l_{r} r}{v_{x}}-\delta_{r r}\right) \\
T_{i}=R_{w} F_{t i}
\end{gathered}
$$

In equation (12), $\beta$ is the vehicle body slip angle.

For the linear model, however, the distributed steering and driving actuators cannot accurately obtain the desired tyre force when the tyre is working in the non-linear tyre region. Thus, new slip ratio and the slip angle controllers of each individual wheel are proposed in this section to deal with the non-linear characteristics of the tyre. Specifically, a PI slip ratio controller and a PI slip angle controller are designed for each wheel. The PI longitudinal slip ratio controller is defined as follows:

$$
\Delta T_{i}=K_{\text {sip }}\left(s_{i d}-s_{i}\right)+K_{s i i} \int\left(s_{i d}-s_{i}\right)
$$

where $\Delta T_{i}$ is the adjusted driving torque of each wheel, which is added into the distributed driving torque $T_{i}$ obtained from the linear model (13). $s_{i}$ represents the actual slip ratio obtained from the vehicle dynamics model and $s_{d i}$ represents the desired slip ratio considering non-linear tyre characteristics. $K_{\text {sip }}$ is the proportional control gain and $K_{s i i}$ is the integral control gain.

Remark 1: It should be noted that based on the theory of PID (proportional, integral, and derivative) controllers, the simple P controller, the PI controller and the PID controller have all been considered and tested in this study. Doing this, however, showed that the PI controller could decrease the convergence steps more efficiently than the P controller, and the PID controller was only marginally better than the PI controller. For these reasons, the PI controller is used here. 
The PI lateral slip angle controller is presented as:

$$
\Delta \delta_{i}=K_{a i p}\left(a_{i d}-a_{i}\right)+K_{a i i} \int\left(a_{i d}-a_{i}\right)
$$

where $\Delta \delta_{i}$ is the adjusted steering angle of each wheel, which is added into the distributed steering angle $\delta_{i}$ calculated from the linear model (12). $a_{i}$ represents the actual slip angle of the individual wheel obtained from the vehicle dynamics model and $a_{d i}$ represents the desired slip angle of the individual wheel when considering the non-linear tyre characteristics. $K_{\text {aip }}$ is the proportional control gain and $K_{a i i}$ is the integral control gain.

It should be noted that the desired wheel slip angle and slip ratio are calculated by the inverse Dugoff tyre model (16) according to equation (5), and the actual values of the slip angle and the slip ratio are obtained from the vehicle dynamics model and assumed to be known in this study. Note that the desired slip ratio $s_{d i}(t)$ and slip angle $a_{d i}(t)$ at the current time instance need the information from previous samples $s_{d i}(t-1)$ and $f(\lambda)(t-1)$.

$$
\begin{gathered}
s_{d i}(t)=\frac{F_{t i}(t)\left(1-s_{d i}(t-1)\right)}{C_{s} f(\lambda)(t-1)} \\
a_{d i}(t)=\tan ^{-1} \frac{F_{s i}(t)\left(1-s_{d i}(t-1)\right)}{C_{a} f(\lambda)(t-1)}
\end{gathered}
$$

Remark 2: Estimation of the longitudinal velocity, longitudinal slip ratio, friction coefficient and lateral slip angle of the vehicle has been done previously [24][25][26]. Thus, in this paper, the longitudinal velocity of the vehicle, the longitudinal slip ratio and lateral slip angle of the tyre are assumed to be known. Specifically, the individual wheel slip ratio $s_{i}$ can be calculated by the following equations [27]:

$$
\begin{array}{cl}
S_{i}=\frac{R_{\omega} \omega_{i}-v_{x}}{R_{\omega} \omega_{i}} & \text { during acceleration } \\
S_{i}=\frac{R_{\omega} \omega_{i}-v_{x}}{v_{x}} & \text { during braking }
\end{array}
$$

where $R_{\omega}$ is the wheel radius, $\omega_{i}$ is the wheel angular velocity and $v_{x}$ is the longitudinal velocity. $i=f l, f r, r l, r r$, which represents the front left, front right, rear left and rear right wheel, respectively. To estimate the slip ratio $s_{i}$, wheel angular velocity can be easily measured by the motor encoder of the electric vehicle and the vehicle longitudinal velocity can be estimated by the method proposed in [27]. Although that study only focused on pure longitudinal motion, a number of other studies have also proposed methods for estimating longitudinal velocity and lateral velocity during cornering motion. [28][29] Because this paper only focuses on the tyre force optimal distribution and control, the detailed slip ratio estimation method is not discussed here.

The method for estimating the individual wheel slip angle is based on the measurement of steering current and steering angle from the individual wheel steering motor of the electric vehicle. According to steering current and steering angle, the individual wheel total aligning moment can be estimated, and finally the individual wheel side-slip angle can be estimated. The detailed description of this estimation method can be found in [30]. 
Figure 3 shows the whole system diagram of the longitudinal slip ratio and lateral slip angle PI controllers in the lower level control system, which are described by equations (12)-(16). When the PI controllers are applied, the controlled steering and driving actuators will interact with the vehicle motion according to the non-linear dynamics model.

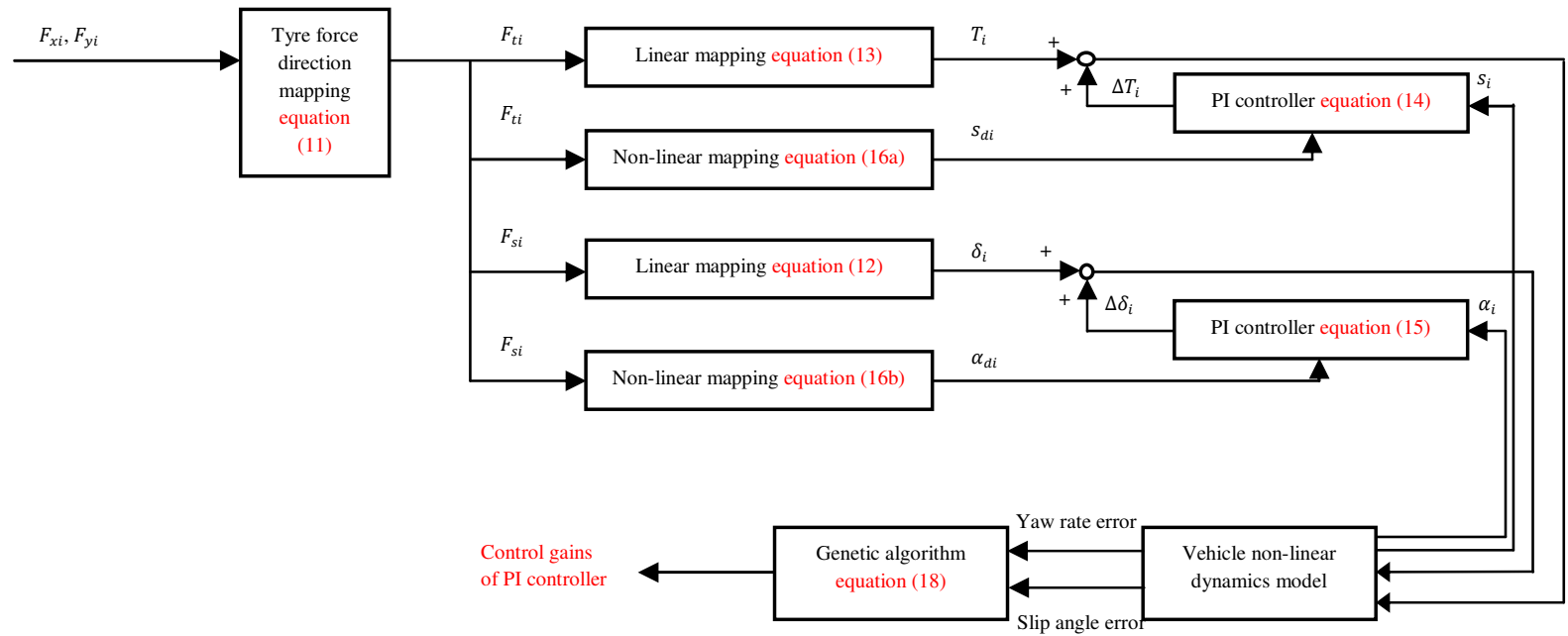

Figure 3. Block diagram of the lower level distribution control system.

\subsection{Application of GA to determine the control gains of PI controllers}

In the slip ratio and slip angle controllers, there are a total of 16 feedback control gains which must be determined. These control gains are difficult to find by trial-and-error. GA is applied here to optimally determine the control feedback gains. For the use of GA, a solution domain and the fitness function are required. For the proposed PI slip ratio and slip angle controllers, the solution domain of the control gains is defined as positive. The fitness function $J_{2}$ is determined by the following equation:

$$
J_{2}=\sum_{t=0}^{T}\left(A e_{y a w \_r a t e}^{2}+B e_{\text {slip_angle }}^{2}\right)
$$

where $e_{\text {yaw_rate }}$ represents the difference between the desired yaw rate and the actual yaw rate when the non-linear control method is applied. $e_{\text {slip_angle }}$ represents the difference between the desired zero body slip angle and the actual vehicle body slip angle when the nonlinear control method is applied. $A$ and $B$ are the scaling factors of the yaw rate error and slip angle error. The range of the scaling factors is between 0 and 1 . The default value of $A$ and $B$ 
is 1 . This value can be decreased so that the corresponding term has less weight in the optimal cost function $J_{2}$.

Simulations of vehicle motion are conducted to calculate the fitness function and the optimal solution can be determined after a number of fitness functions have been calculated and evaluated. Specifically, based on the solution domain, the initial random populations, which are the control gains of the PI controllers, are generated first. The fitness of each solution is then evaluated based on equation (18) and the most suitable parents are selected. Then the child solutions are created from the selected parents using single point crossover and the children solutions are subjected to the crossover and mutation operations. Finally, the parent generation is replaced by the child generation and the evaluation cycle continues until the termination criterion is met and the results of control gains are determined. [17] In this study, the termination criterion is that either the maximum generation is reached or the tolerance of the fitness function is met. Figure 4 shows the whole working procedure of GA.

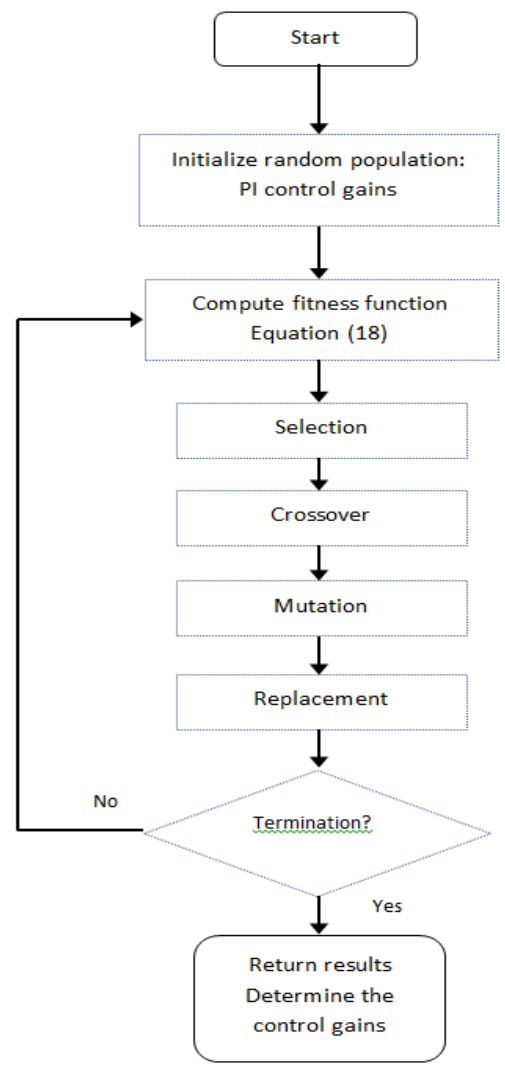

Figure 4. Flow chart of GA.

\section{Simulation RESUlts}

To test the dynamics performance of the suggested optimal non-linear control allocation method, numerical simulations are conducted in various vehicle moving conditions. The parameter values used in the simulations are listed in Table 1. First, the preliminary 
simulations are conducted to determine the 16 control gains of the PI controllers using GA. Then, simulations are conducted to test the control performance under various conditions.

Table 1. Parameter values used in simulations.

\begin{tabular}{|c|c|c|}
\hline$m$ & Mass & $1298.9 \mathrm{~kg}$ \\
\hline$l_{f}$ & $\begin{array}{c}\text { Distance of c.g. from } \\
\text { the front axle }\end{array}$ & $1 \mathrm{~m}$ \\
\hline$l_{r}$ & $\begin{array}{c}\text { Distance of c.g. from } \\
\text { the rear axle }\end{array}$ & $1.454 \mathrm{~m}$ \\
\hline$b_{f}$ & Front track width & $1.436 \mathrm{~m}$ \\
\hline$b_{r}$ & Rear track width & $1.436 \mathrm{~m}$ \\
\hline$C_{s}$ & $\begin{array}{c}\text { Longitudinal stiffness } \\
\text { of the tyre }\end{array}$ & $\begin{array}{l}50000 \\
\text { N/unit slip } \\
\text { ratio }\end{array}$ \\
\hline$I_{z}$ & $\begin{array}{c}\text { Vehicle moment of } \\
\text { inertial about yaw } \\
\text { axle }\end{array}$ & $1627 \mathrm{kgm}^{2}$ \\
\hline$R_{\omega}$ & Wheel radius & $0.35 \mathrm{~m}$ \\
\hline$I_{\omega}$ & $\begin{array}{c}\text { Wheel moment of } \\
\text { inertial }\end{array}$ & $2.1 \mathrm{kgm}^{2}$ \\
\hline$\varepsilon_{r}$ & $\begin{array}{l}\text { Road adhesion } \\
\text { reduction factor }\end{array}$ & $0.015 \mathrm{~s} / \mathrm{m}$ \\
\hline$C_{\alpha}$ & $\begin{array}{c}\text { Cornering stiffness of } \\
\text { the tyre }\end{array}$ & $\begin{array}{l}30000 \\
\mathrm{~N} / \mathrm{rad}\end{array}$ \\
\hline$A$ & $\begin{array}{l}\text { Scaling factor of yaw } \\
\text { rate error in the } \\
\text { fitness function of } \\
\text { genetic algorithm }\end{array}$ & 1 \\
\hline$B$ & $\begin{array}{l}\text { Scaling factor of body } \\
\text { slip angle error in the } \\
\text { fitness function of } \\
\text { genetic algorithm }\end{array}$ & 1 \\
\hline$a$ & $\begin{array}{l}\text { Scaling factors in the } \\
\text { cost function of upper } \\
\text { level controller }\end{array}$ & 1 \\
\hline$b$ & $\begin{array}{l}\text { Scaling factors in the } \\
\text { cost function of upper } \\
\text { level controller }\end{array}$ & 1 \\
\hline
\end{tabular}




\begin{tabular}{|l|c|c|}
\hline$c$ & $\begin{array}{c}\text { Scaling factors in the } \\
\text { cost function of upper } \\
\text { level controller }\end{array}$ & 1 \\
\hline$d$ & $\begin{array}{c}\text { Scaling factors in the } \\
\text { cost function of upper } \\
\text { level controller }\end{array}$ & 1 \\
\hline
\end{tabular}

\subsection{Preliminary simulations to determine the control gains}

In the GA, the domain of the proportional control gain is $(0,100)$ and the domain of the integral control gain is $(0,100)$. The population is set as 50 and the generation is 150 . To calculate the fitness function, the conditions of the preliminary simulations must be chosen. These must be chosen carefully since it is expected that the control gains determined in the preliminary simulations can apply to the controllers used in various vehicle moving conditions. In this study, three sets of preliminary simulations are conducted at different initial longitudinal velocities in order to determine the control gains, which are $10 \mathrm{~m} / \mathrm{s}, 12.5$ $\mathrm{m} / \mathrm{s}$ and $15 \mathrm{~m} / \mathrm{s}$. Based on these three preliminary simulations, only the vehicle dynamics performance with the velocity between $10 \mathrm{~m} / \mathrm{s}$ and $15 \mathrm{~m} / \mathrm{s}$ is examined in this simulation section as examples. Vehicle motion with velocity beyond this range can be analysed using a similar approach but is not to be discussed in this paper.

In the first preliminary simulation, the initial velocity is $10 \mathrm{~m} / \mathrm{s}$ and the friction coefficient is 0.9. The vehicle is performing a J-turn manoeuvre and the steering input is shown in Figure 5.

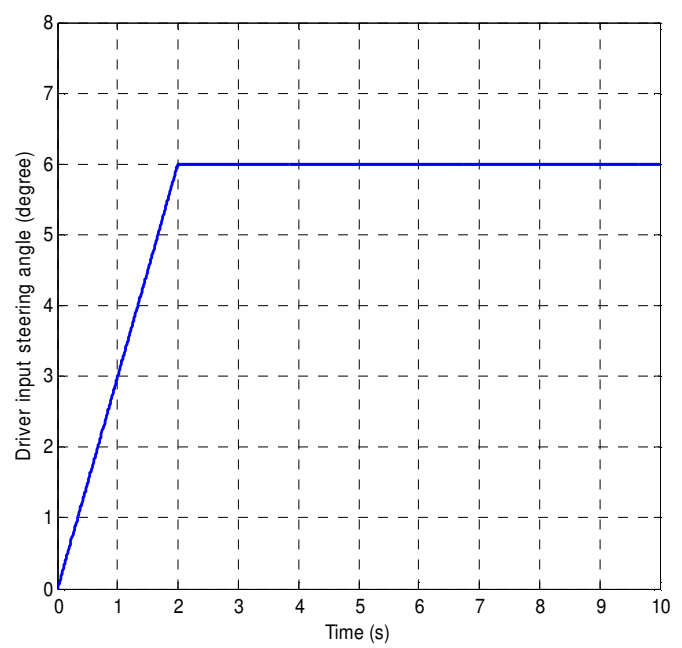

Figure 5. Driver's input steering angle during a J-turn manoeuvre.

As the generation number increases, cost function $J_{2}$ in equation (18) decreases, as shown in Figure 6 . The finally determined control gains are shown in Table 2. 
Table 2. Determined PI control gains in the first preliminary simulation

\begin{tabular}{|c|c|c|c|}
\hline$K_{\text {sflp }}$ & 3.6991 & $K_{\text {sfrp }}$ & 1.1656 \\
\hline$K_{\text {sfli }}$ & 2.4235 & $K_{\text {sfri }}$ & 7.0466 \\
\hline$K_{\text {srlp }}$ & 5.4314 & $K_{\text {srrp }}$ & 7.0470 \\
\hline$K_{\text {srli }}$ & 3.7549 & $K_{\text {srri }}$ & 2.4243 \\
\hline$K_{\text {aflp }}$ & 3.5468 & $K_{\text {afrp }}$ & 1.5596 \\
\hline$K_{\text {afli }}$ & 13.8790 & $K_{\text {afri }}$ & 14.9479 \\
\hline$K_{\text {arlp }}$ & 6.0527 & $K_{\text {arrp }}$ & 2.1615 \\
\hline$K_{\text {arli }}$ & 0.0567 & $K_{\text {arri }}$ & 6.3381 \\
\hline
\end{tabular}

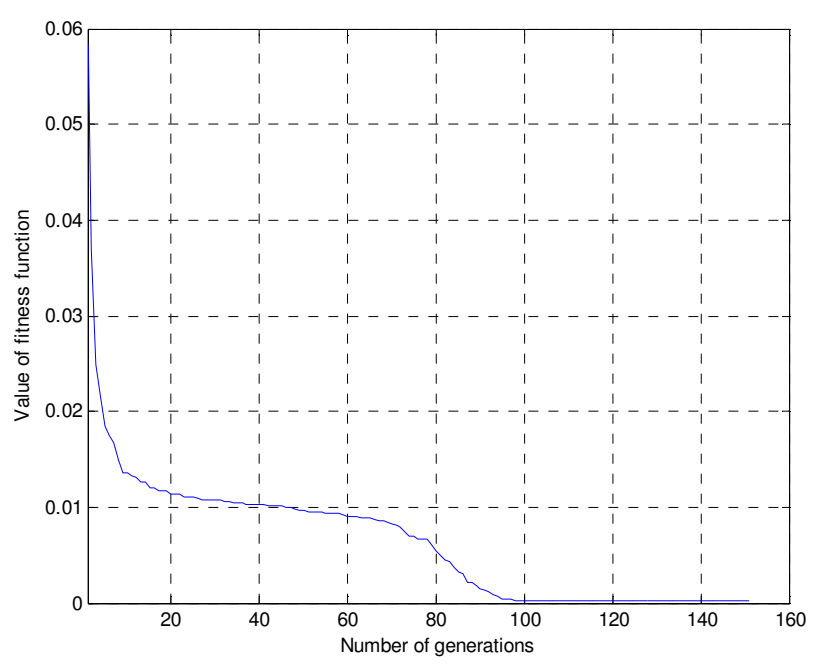

Figure 6. The evolution of cost function $J_{2}$.

In the same manner, the second and third preliminary simulations are conducted and the PI control gains are summarised in Tables 3 and 4.

Table 3. Determined PI control gains in the second preliminary simulation

\begin{tabular}{|c|c|c|c|}
\hline$K_{\text {sflp }}$ & 9.3171 & $K_{\text {sfrp }}$ & 5.6386 \\
\hline$K_{\text {sfli }}$ & 8.8754 & $K_{\text {sfri }}$ & 7.2875 \\
\hline$K_{\text {srlp }}$ & 12.2399 & $K_{\text {srrp }}$ & 8.1320 \\
\hline$K_{\text {srli }}$ & 9.9795 & $K_{\text {srri }}$ & 11.8256 \\
\hline$K_{\text {aflp }}$ & 17.4289 & $K_{\text {afrp }}$ & 17.2962 \\
\hline$K_{\text {afli }}$ & 24.3627 & $K_{\text {afri }}$ & 18.8589 \\
\hline$K_{\text {arlp }}$ & 0.8027 & $K_{\text {arrp }}$ & 4.5018 \\
\hline$K_{\text {arli }}$ & 0.6040 & $K_{\text {arri }}$ & 0.3321 \\
\hline
\end{tabular}


Table 4. Determined PI control gains in the third preliminary simulation

\begin{tabular}{|c|c|c|c|}
\hline$K_{\text {sflp }}$ & 3.8171 & $K_{\text {sfrp }}$ & 4.6622 \\
\hline$K_{\text {sfli }}$ & 4.7184 & $K_{\text {sfri }}$ & 4.6527 \\
\hline$K_{\text {srlp }}$ & 2.4899 & $K_{\text {srrp }}$ & 7.2317 \\
\hline$K_{\text {srli }}$ & 1.9046 & $K_{\text {srri }}$ & 3.1343 \\
\hline$K_{\text {aflp }}$ & 4.6789 & $K_{\text {afrp }}$ & 9.6797 \\
\hline$K_{\text {afli }}$ & 1.0952 & $K_{\text {afri }}$ & 13.8589 \\
\hline$K_{\text {arlp }}$ & 5.2920 & $K_{\text {arrp }}$ & 4.3330 \\
\hline$K_{\text {arli }}$ & 6.9648 & $K_{\text {arri }}$ & 0.0103 \\
\hline
\end{tabular}

Figure 7 shows the total control error as it changes with the vehicle velocity by using three different groups of control gains in the simulation of simple J-turning. The steering input of the simulation is the same as Figure 5. The total control error is actually the value of fitness function $J_{2}$ which is defined in equation (18). According to Figure 7, the three groups of PI controller gains can all control the vehicle yaw rate and body slip angle well when the velocity is between $10 \mathrm{~m} / \mathrm{s}$ and $15 \mathrm{~m} / \mathrm{s}$. However, each specific group of control gains is better at controlling performance within a specific range of vehicle velocity. The PI control gains in Table 2 can achieve the best control performance between $10 \mathrm{~m} / \mathrm{s}$ and $11.5 \mathrm{~m} / \mathrm{s}$. The control gains in Table 3 and Table 4 can achieve the best control performance during the velocity range $\left[\begin{array}{ll}11.5 & 13.5\end{array}\right] \mathrm{m} / \mathrm{s}$ and $\left[\begin{array}{ll}13.5 & 15\end{array}\right] \mathrm{m} / \mathrm{s}$ respectively. During the transition between any two adjacent velocity ranges, the abrupt change of control gains may deteriorate the control performance. To prevent this kind of problem, the interpolation method can be used. For example, during the transition velocity around $11.5 \mathrm{~m} / \mathrm{s}$, the total transition range is assumed to be $0.5 \mathrm{~m} / \mathrm{s}$ (from $11.25 \mathrm{~m} / \mathrm{s}$ to $11.75 \mathrm{~m} / \mathrm{s}$ ) and the control gains used in the transition period can be calculated as follows:

$$
K_{T}=\frac{11.75-v_{x}}{0.5} K_{1}+\frac{v_{x}-11.25}{0.5} K_{2}
$$

where $K_{T}$ is the group of control gains used in the transition period. $K_{1}$ and $K_{2}$ are groups of control gains given in Table 2 and Table 3 respectively. 


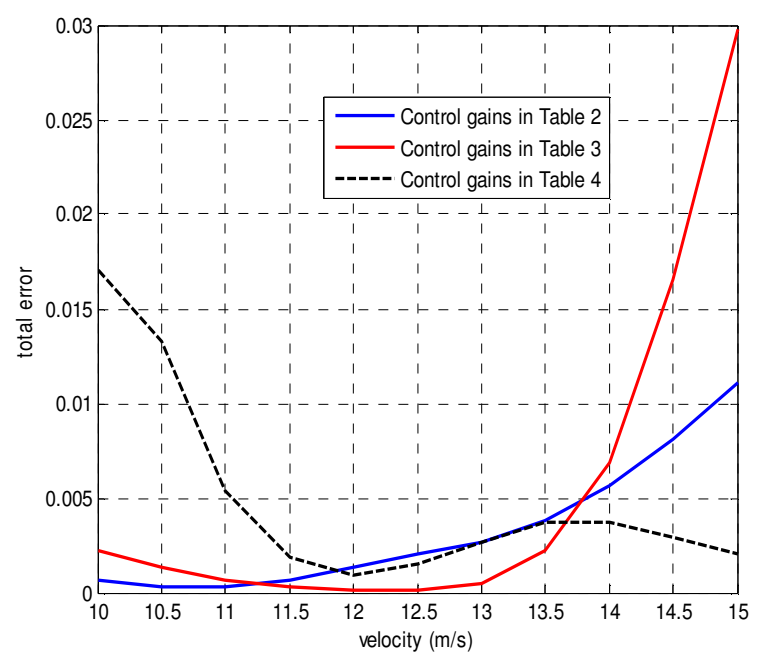

Figure 7. The total control error with respect to vehicle velocity and control gains.

\subsection{Simulation results of the control allocation method}

Once the control gains of the PI controllers have been determined, the optimal non-linear vehicle dynamics controller with the optimal control gains can be tested under various driving conditions.

First, the vehicle performs a J-turn at an initial velocity of $15 \mathrm{~m} / \mathrm{s}$. The PI control gains in Table 4 can be used and the friction coefficient is 0.9 . The driver's input steering angle is the same as in Figure 5. The vehicle yaw rate response and body slip angle response are shown in Figures 8 and 9, respectively. For the purpose of comparison, the simulation result of the linear optimal control allocation method using equations (12) and (13) is also presented. The simulation performance is also presented when no optimal tyre force distribution method is applied. When no tyre force controller is applied, the driver's input steering angle is directly applied to the two front wheels of the vehicle and the driver's input driving torque is equally distributed to the two rear wheels, which is similar to the traditional front wheel steer and rear wheel drive vehicle.

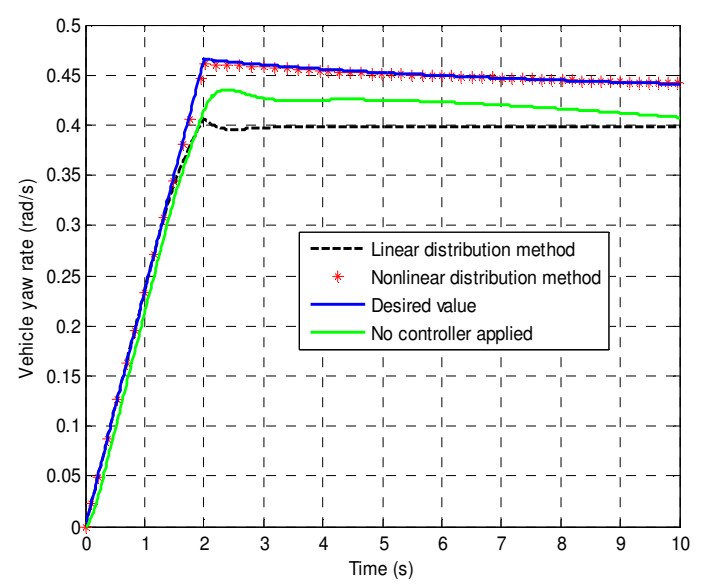


Figure 8 . The vehicle yaw rate response in the J-turn simulation.

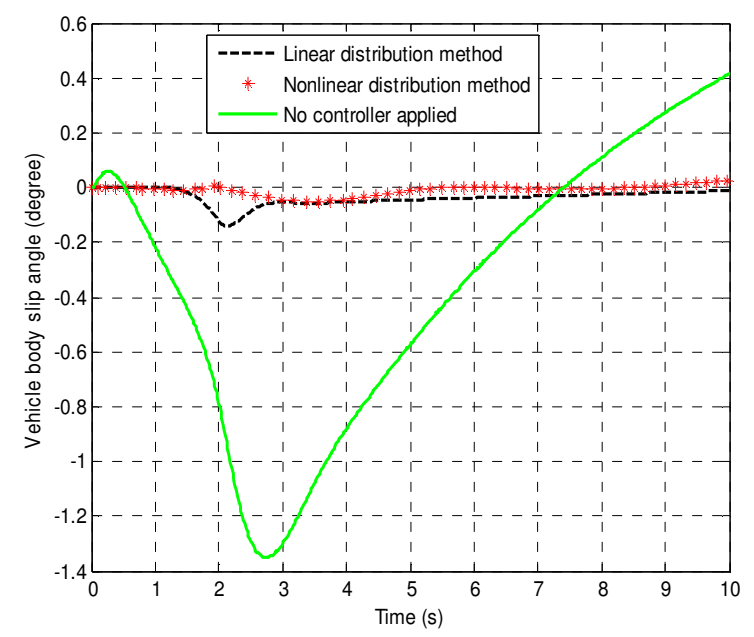

Figure 9. The vehicle body slip angle in the J-turn simulation.

According to Figures 8 and 9, the linear tyre force distribution method performs well in controlling the body slip angle, but the yaw rate response is compromised. This is because the linear method assumes a linear vehicle dynamics relationship, and the non-linear tyre characteristic is neglected. To achieve the desired tyre force, a larger slip angle or slip ratio of the individual wheel is required if the non-linear tyre characteristic is considered. Thus, the output yaw rate obtained from the linear method is smaller than the desired value because a smaller individual slip ratio and slip angle is achieved. The non-linear method considers the non-linear tyre characteristic and consequently the yaw rate achieves the desired value. The body slip angle response in the non-linear method is equal to that achieved in the linear method, but, as explained above, the yaw rate performance of the non-linear method is far better.

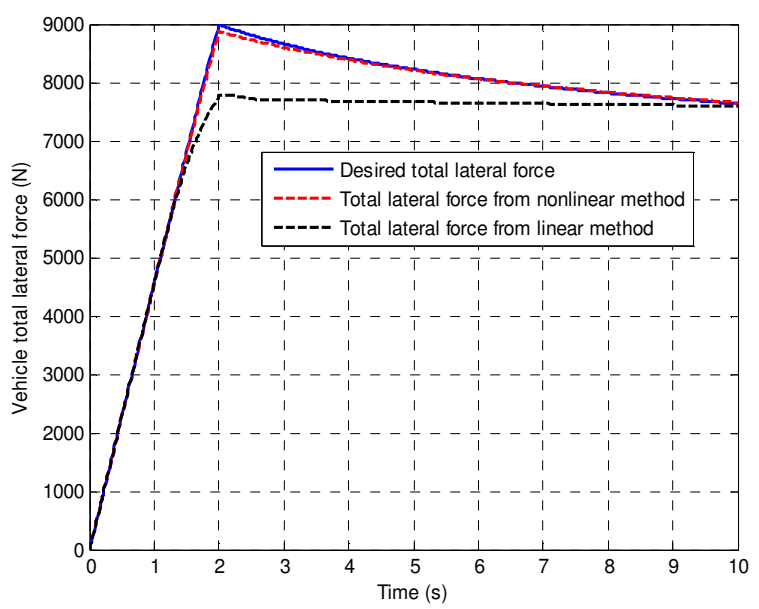

Figure 10. The total lateral tyre force in the J-turn simulation. 


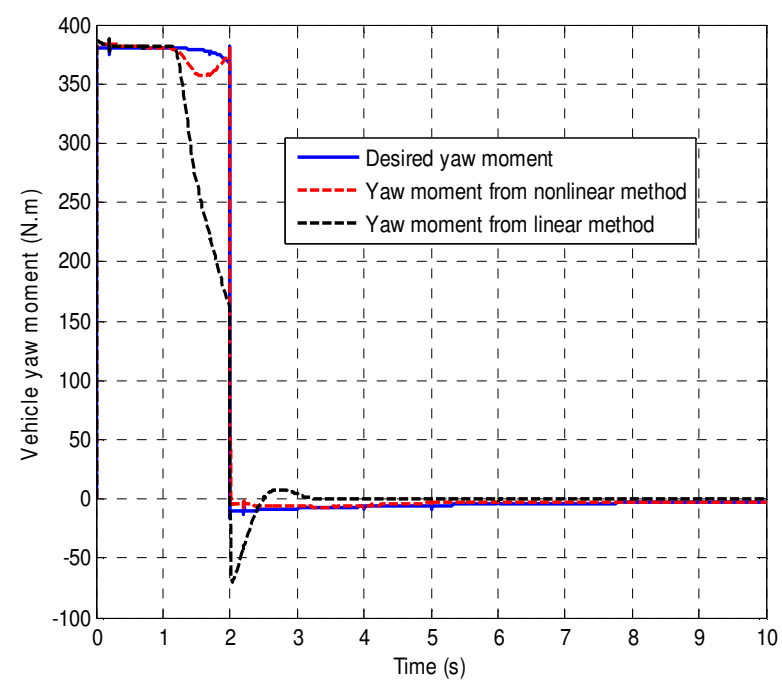

Figure 11. The yaw moment in the J-turn simulation.

In Figures 10 and 11, the non-linear method proposed in this study can achieve the desired total lateral tyre force and yaw moment. According to equations 8(a) and 8(b), if the desired total lateral tyre force and yaw moment are achieved, the desired yaw rate and body slip angle can be achieved, as shown in Figure 8 and Figure 9. When the linear method is applied, the total lateral tyre force and yaw moment cannot reach the desired value because of the non-linear tyre characteristic. This means that the desired yaw rate cannot be achieved. This is shown in Figure 8. It should be noted that there is a small difference between the total lateral force and yaw moment controlled by the non-linear method and the desired values at 2 seconds, as shown in Figures 10 and 11, and this causes the small difference between the yaw rate controlled by the non-linear method and the desired value in 2 seconds in Figure 8 . In Figures 12 and 13, the individual wheel slip angle controller and the slip ratio controller are proved to successfully achieve the desired values in the non-linear method.

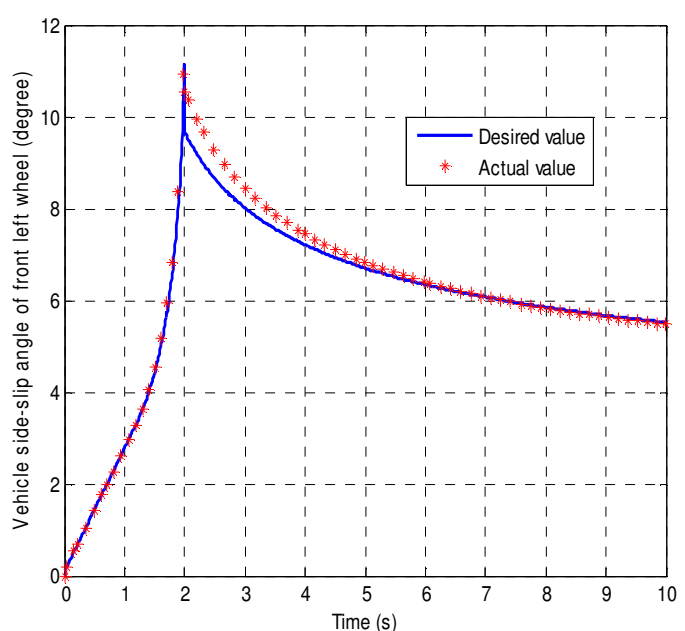

(a)

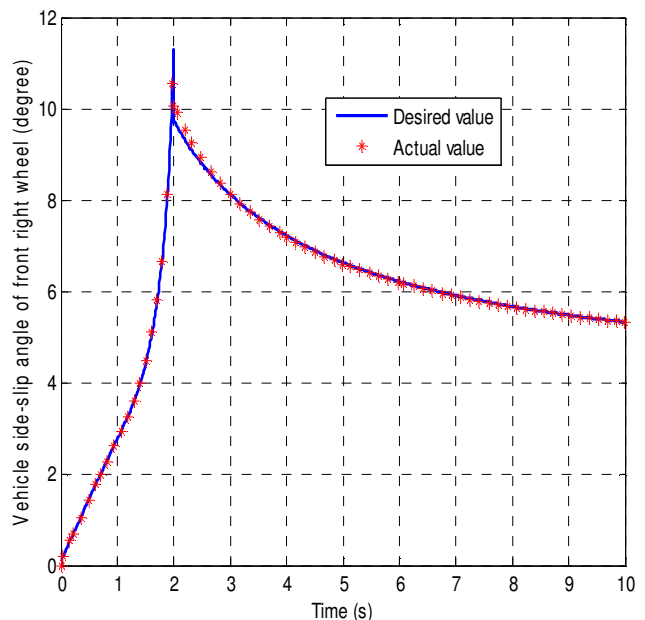

(b) 


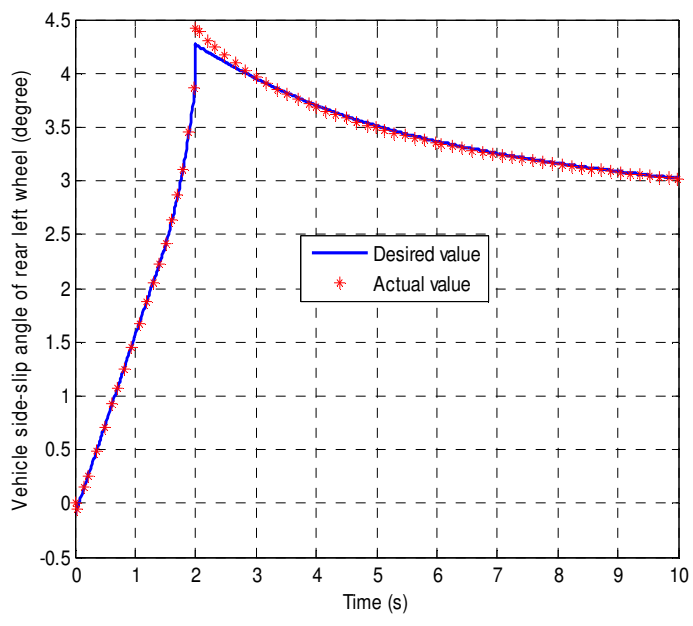

(c)

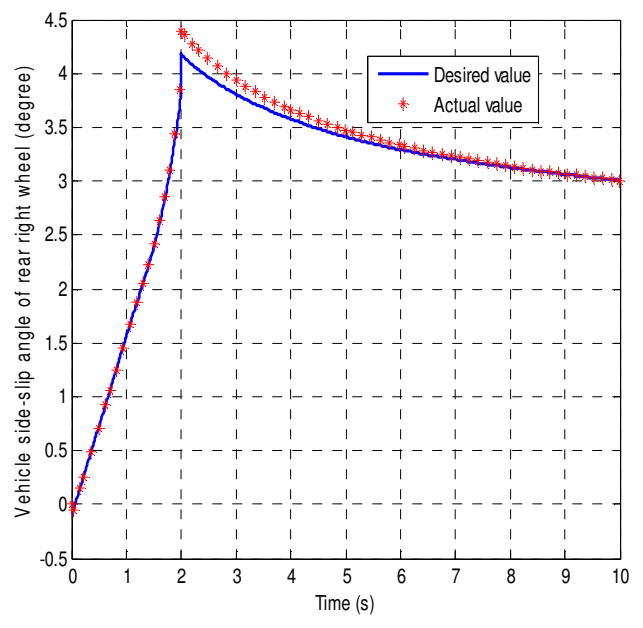

(d)

Figure 12. The individual wheel side-slip angle in the J-turn simulation controlled by the nonlinear method: (a) front left wheel (b) front right wheel (c) rear left wheel (d) rear right wheel.

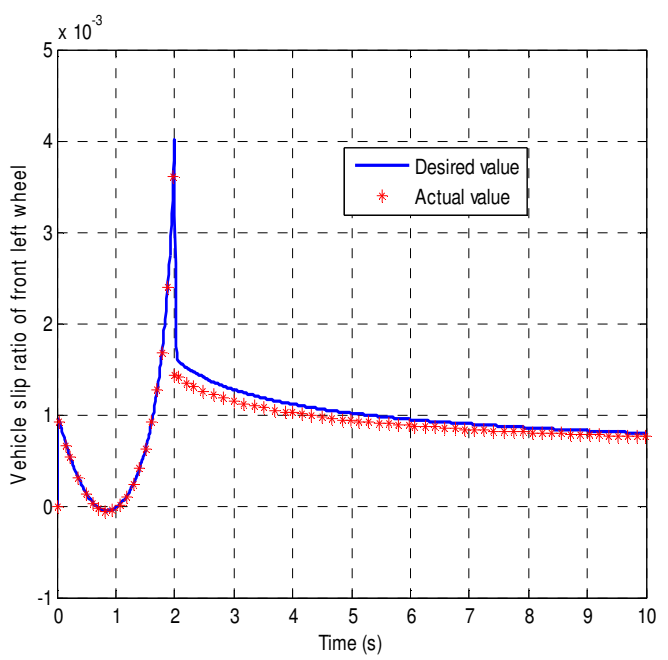

(a)

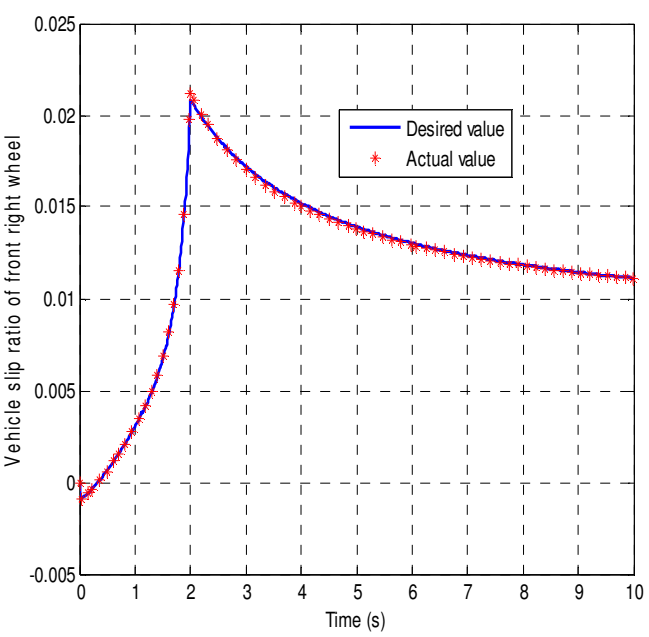

(b) 


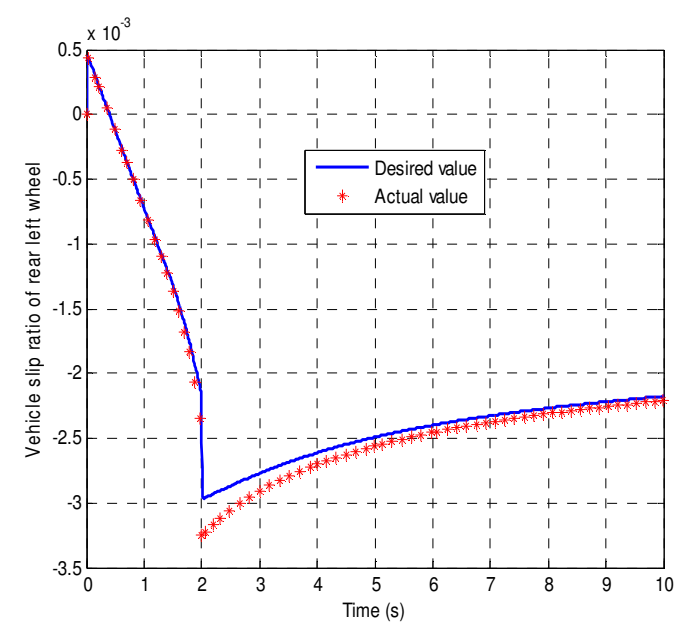

(c)

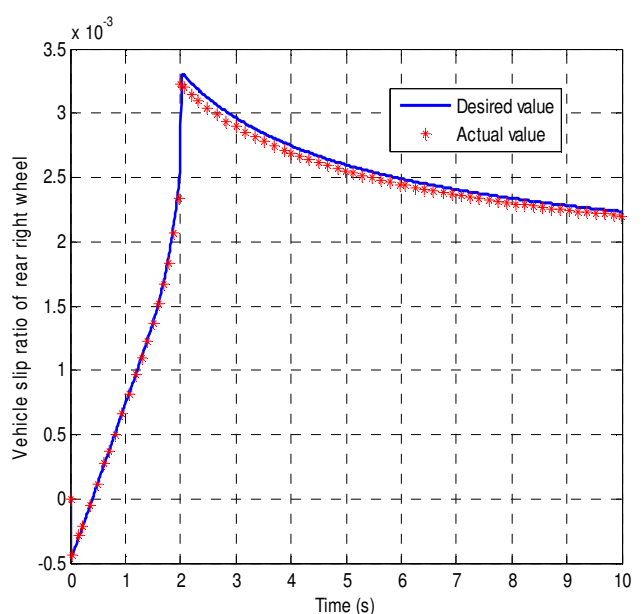

(d)

Figure 13. The individual wheel slip ratio in the J-turn simulation controlled by the non-linear method: (a) front left wheel (b) front right wheel (c) rear left wheel (d) rear right wheel.

The second simulation is the lane change motion. The initial vehicle velocity is changed to 10 $\mathrm{m} / \mathrm{s}$ and the PI control gains in Table 2 are used. The friction coefficient is the same as simulation 1. The driver's input steering angle is shown in Figure 14.

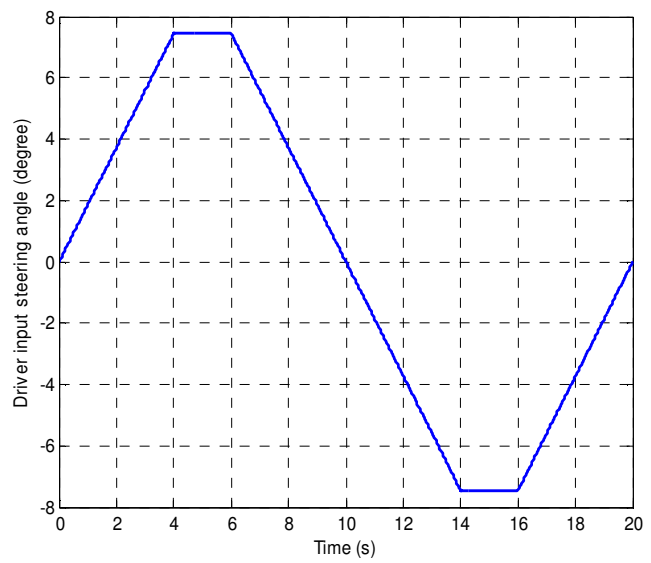

Figure 14. Driver's steering input in the lane change simulation. 


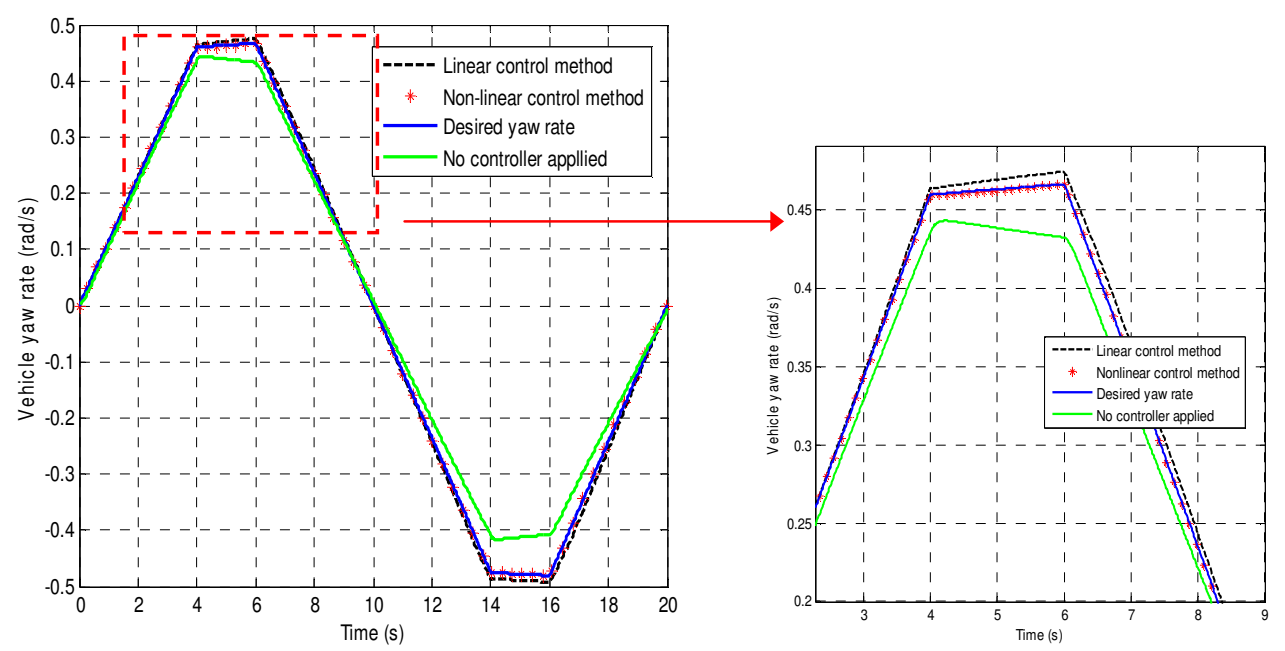

Figure 15. The vehicle yaw rate response in the lane change simulation.

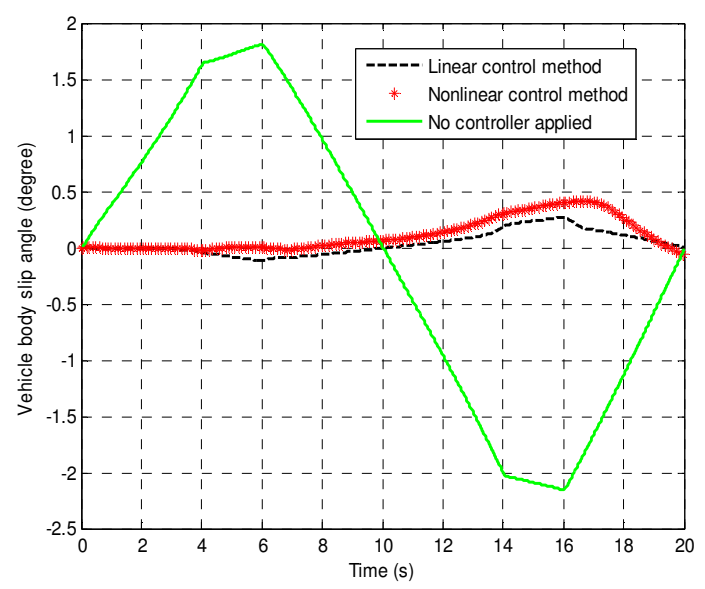

Figure 16. The vehicle body slip angle in the lane change simulation.

Figures 15 and 16 show the simulation results of yaw rate and body slip angle. We can see in Figures 15 and 16 that the linear method and non-linear method both have good performance in terms of yaw rate and body slip angle control. In Figure 15, the non-linear method can achieve accurate yaw rate control, but the yaw rate control performance of the linear method is a little compromised. It is noted that the vehicle body slip angle control performance of the non-linear method is not as good as the linear method in Figure 16. This is because the PI control gains used in the simulation of Figure 16 are determined based on the J-turn manoeuvre at $10 \mathrm{~m} / \mathrm{s}$ as given in Table 2. Although the simulation of Figure 16 is for the lane change motion, the compromised control performance is acceptable and the control gains determined in the J-turn manoeuvre are proved to successfully apply to the lane change motion under the same vehicle velocity condition. 

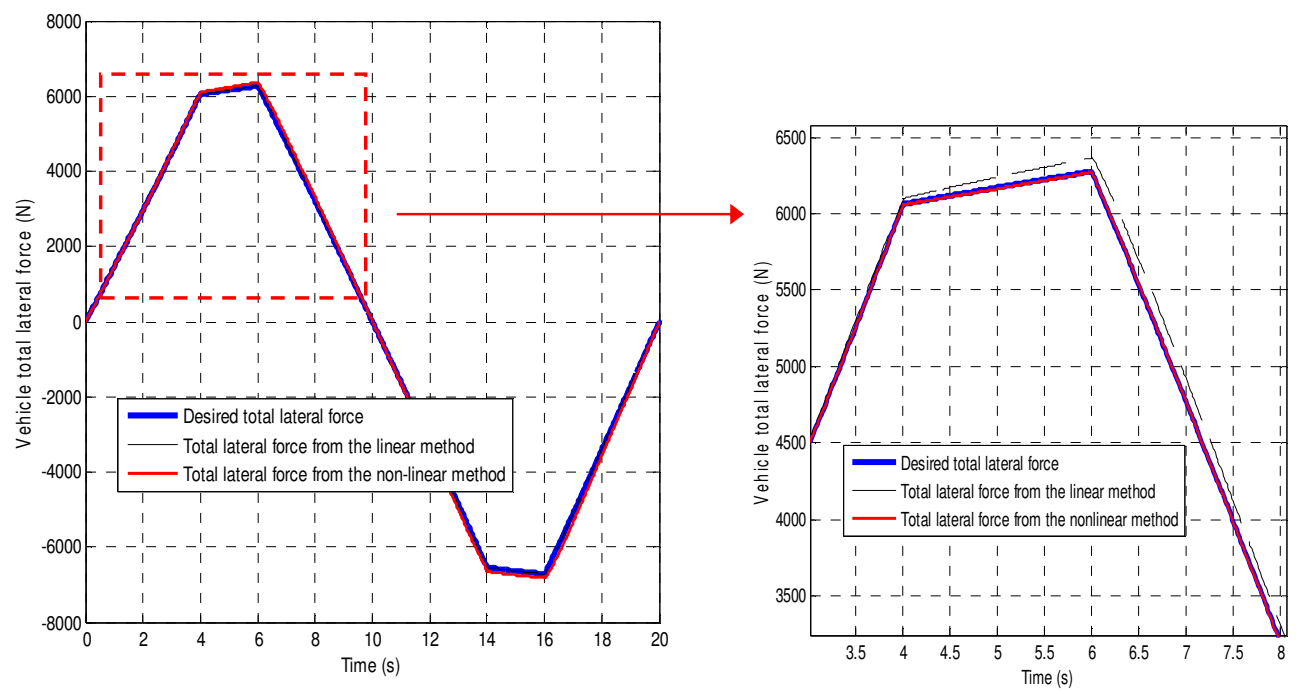

Figure 17. The total lateral tyre force in the lane change simulation.

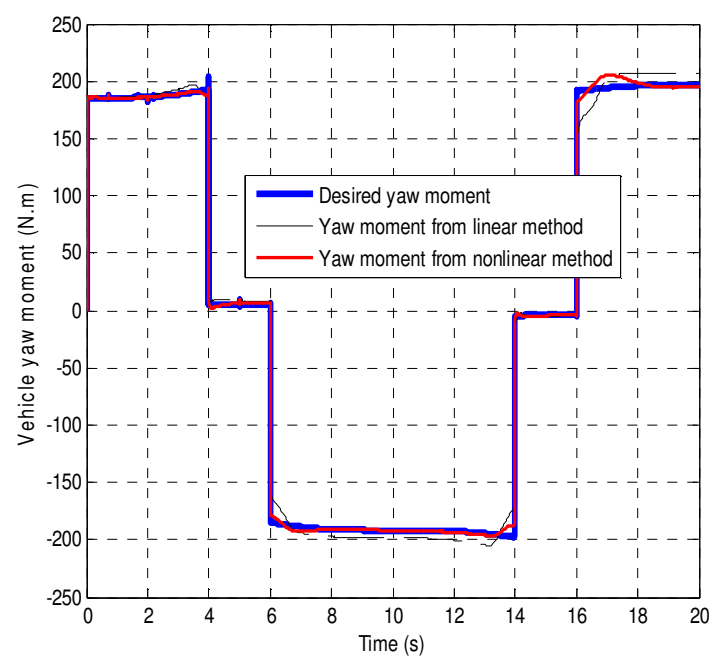

Figure 18. The vehicle yaw moment in the lane change simulation.

Figures 17 and 18 suggest that the non-linear method has the better performance of achieving the desired total lateral tyre force and yaw moment compared with linear method, which proves to have better yaw rate control performance in Figure 15. It is noted that the controlled yaw moment of non-linear method between 16 and 18 seconds in Figure 18 has small disturbance, which causes the increased body slip angle controlled by the non-linear method around 16 seconds in Figure 16. Figures 19-20 show that the desired individual wheel slip angle and slip ratio can be well tracked using the non-linear method. 


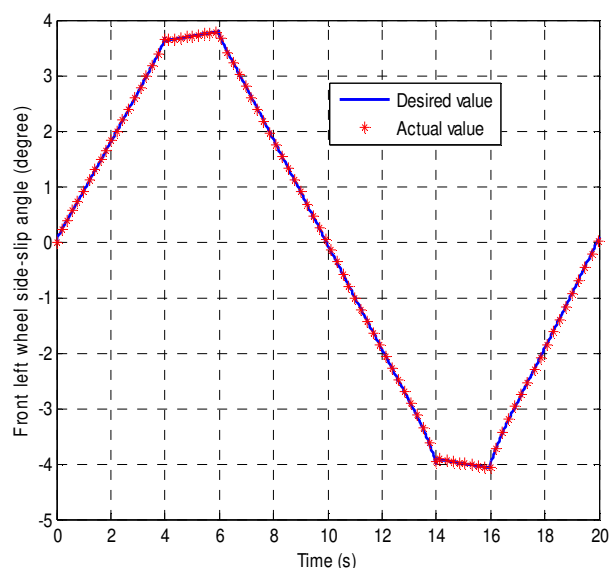

(a)

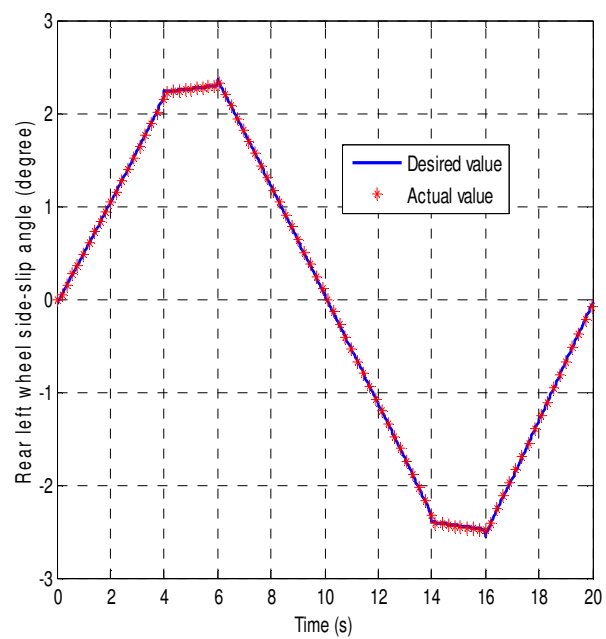

(c)

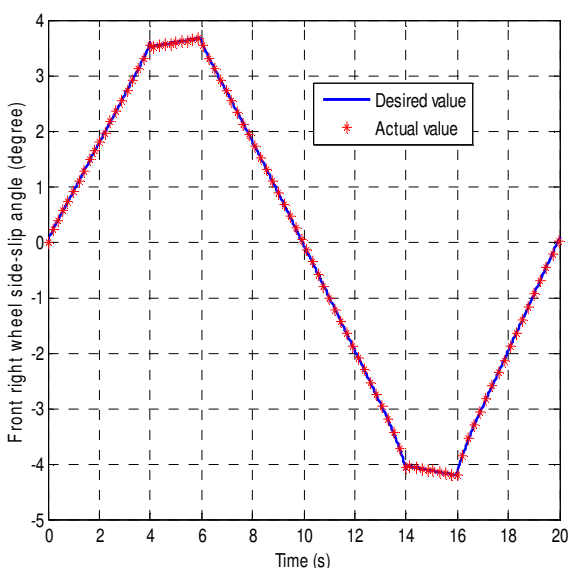

(b)

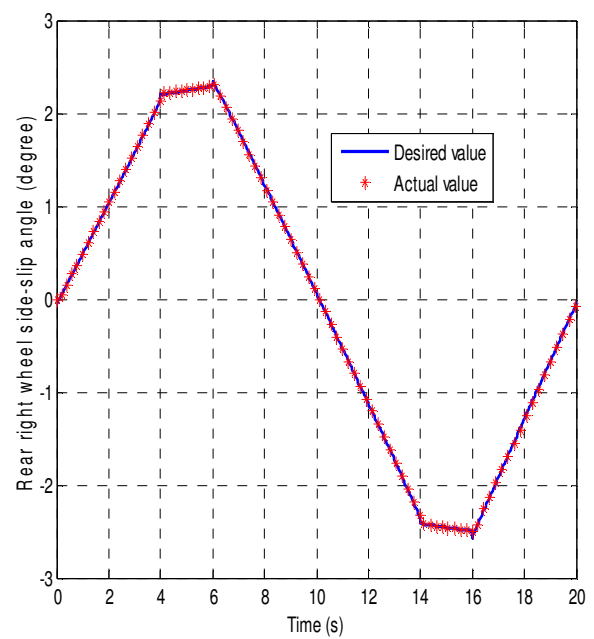

(d)

Figure 19. The individual wheel slip angle in the lane change simulation controlled by the non-linear method: (a) front left wheel (b) front right wheel (c) rear left wheel (d) rear right wheel.

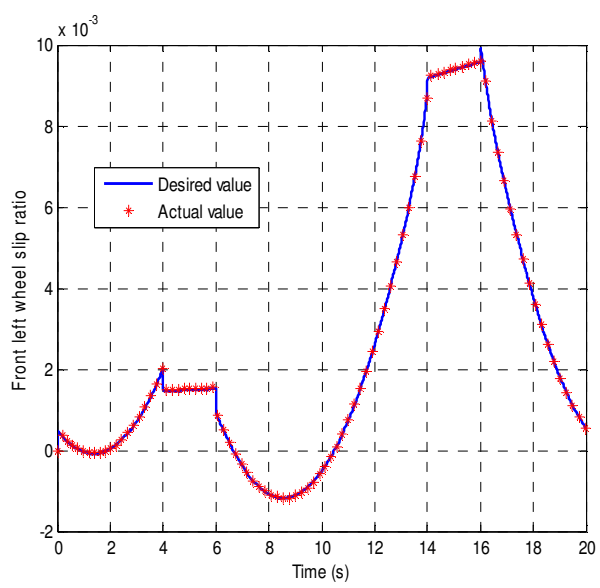

(a)

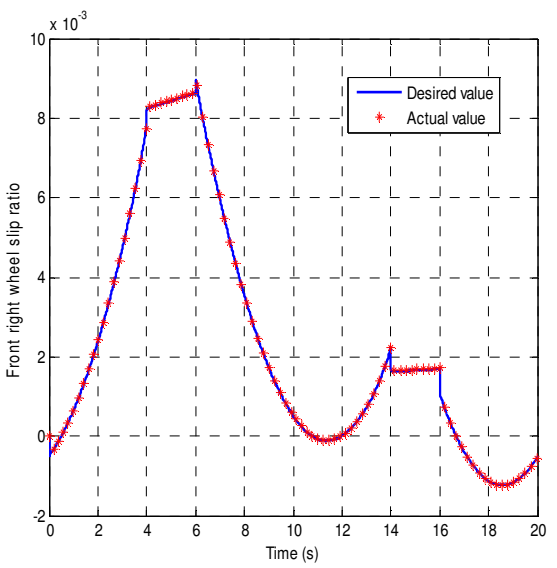

(b) 


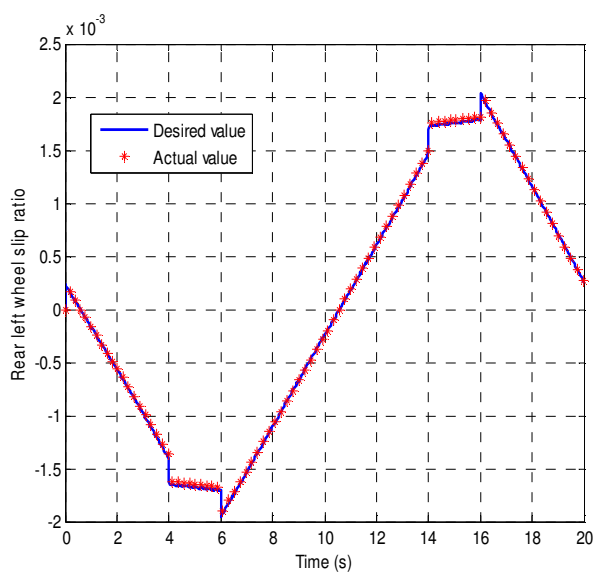

(c)

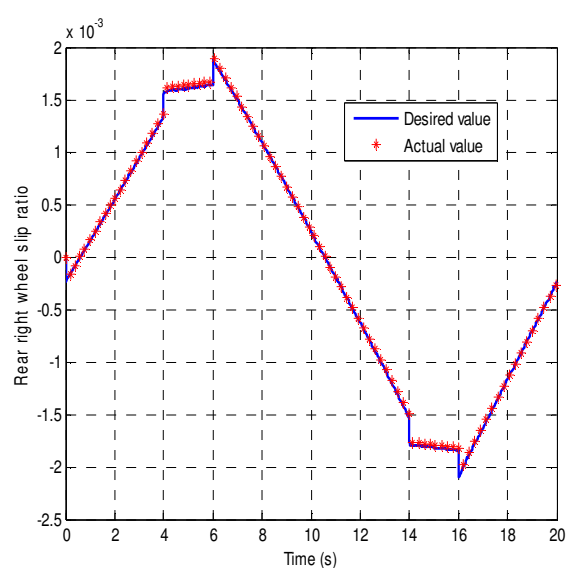

(d)

Figure 20. The individual wheel slip ratio in the lane change simulation controlled by the non-linear controller: (a) front left wheel (b) front right wheel (c) rear left wheel (d) rear right wheel.

The third simulation is the combined traction and steering motion. The initial velocity of the vehicle is $10 \mathrm{~m} / \mathrm{s}$ and the control gains in Table 2 are used. The friction coefficient is still 0.9 . The driver is still performing the J-turn manoeuvre, but the acceleration pedal is also pushed simultaneously. The input steering angle is the same as Figure 5 and the input driving torque is shown in Figure 21.

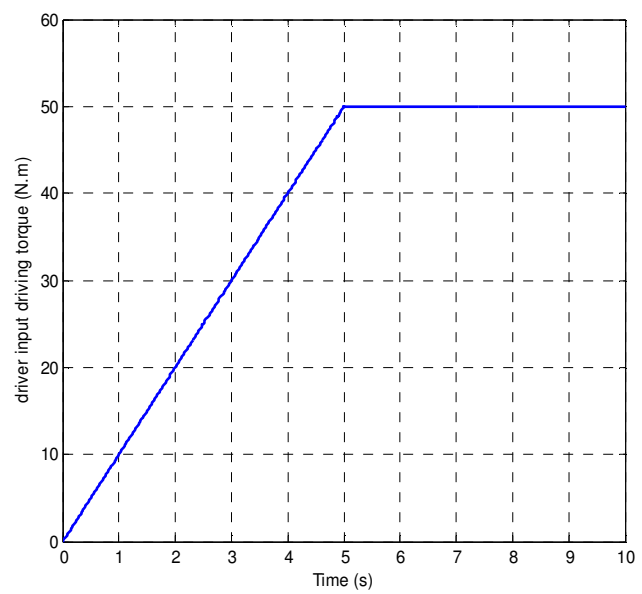

Figure 21. The input driving torque during the combined driving and steering motion. 


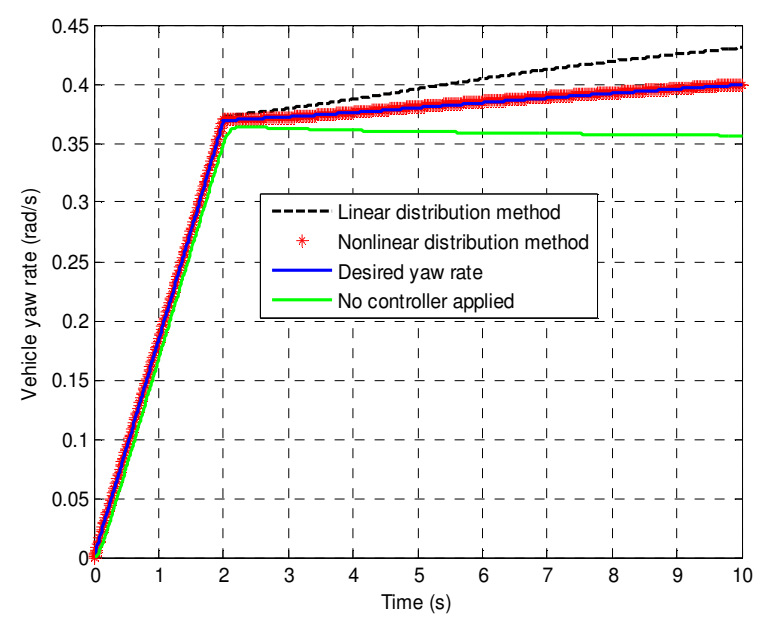

Figure 22. The vehicle yaw rate response during the combined driving and steering motion.

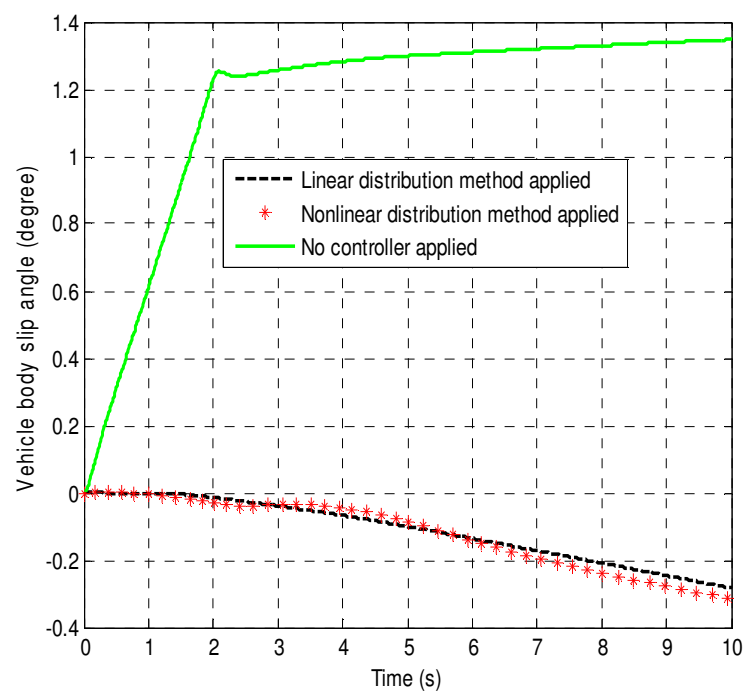

Figure 23. The vehicle body slip angle response during the combined driving and steering motion.

Figure 22 and Figure 23 show the vehicle yaw rate and body slip angle responses. The desired yaw rate is increased, since the driver's input traction torque is applied and vehicle longitudinal velocity is increased. The non-linear method can achieve the desired yaw moment and yaw rate. For the linear method, the distributed tyre slip angle is larger than the desired value, which causes the larger distributed lateral force and yaw rate. For the no controller applied situation, the yaw rate response does not increase with time but even decreases. This is because even when traction torque is applied, the increased longitudinal velocity caused by the increased driving force cannot overcome the decreased velocity caused by the vehicle turning without the distribution of the controlled tyre force. In addition, the linear method and non-linear method both have the good control performance of body slip angle. 
Figure 24 and Figure 25 show that non-linear method achieve good control performance of total lateral tyre force and yaw moment, which leads to the good control performance of yaw rate and body slip angle. The linear method has larger distributed total lateral tyre force and the consequently yaw rate control performance is compromised. Figures 26-27 also demonstrate that the desired individual wheel slip angle and slip ratio can be achieved using the non-linear method.

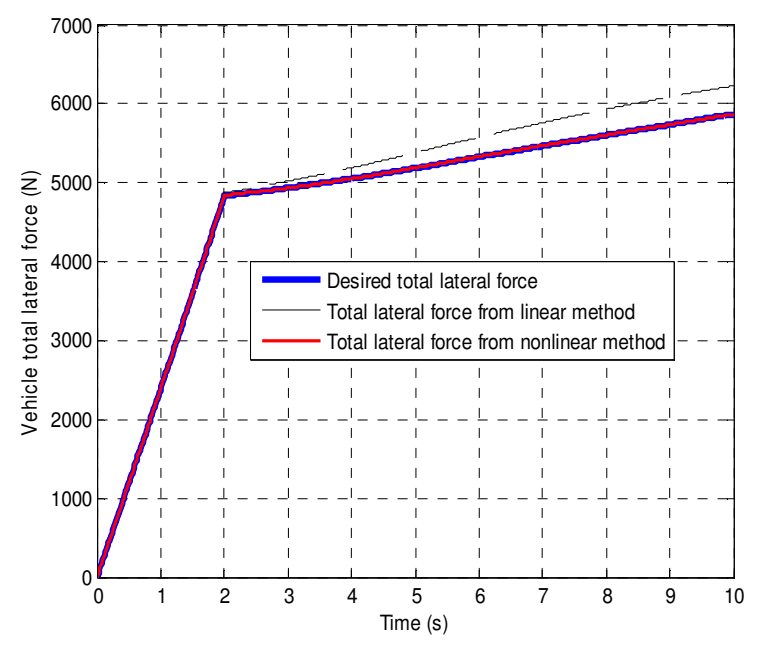

Figure 24. The vehicle total lateral tyre force during the combined driving and steering motion.

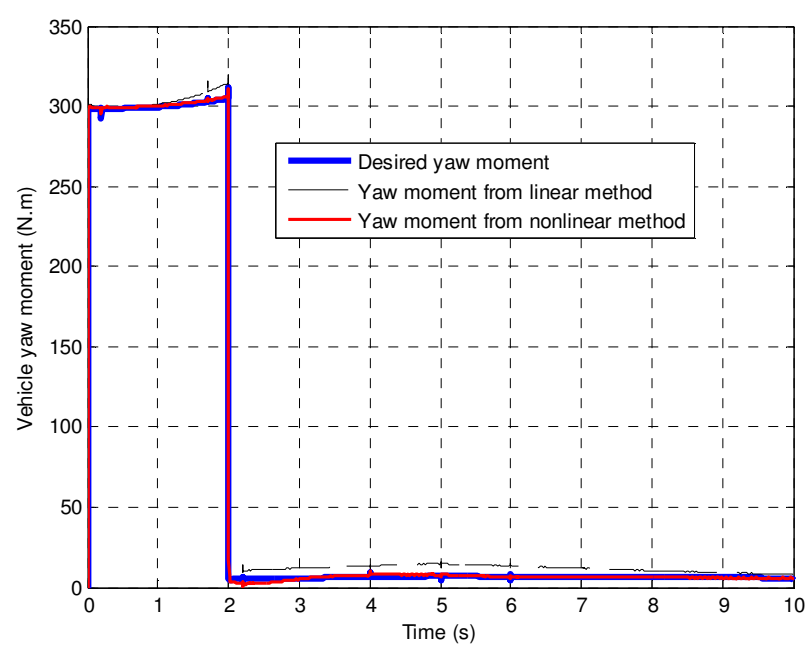

Figure 25. The vehicle yaw moment during the combined driving and steering motion. 


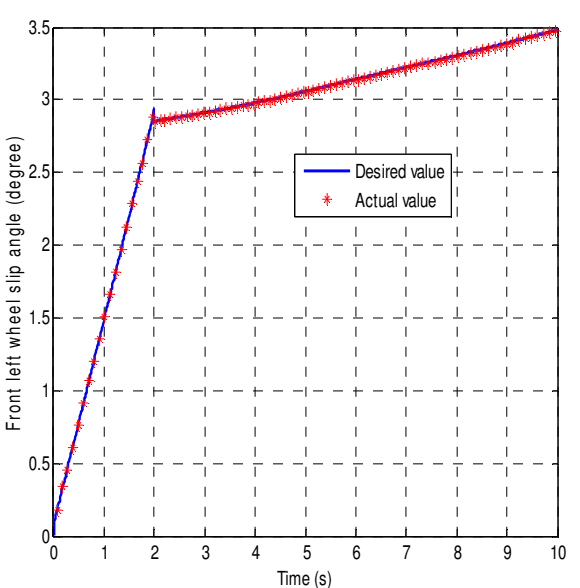

(a)

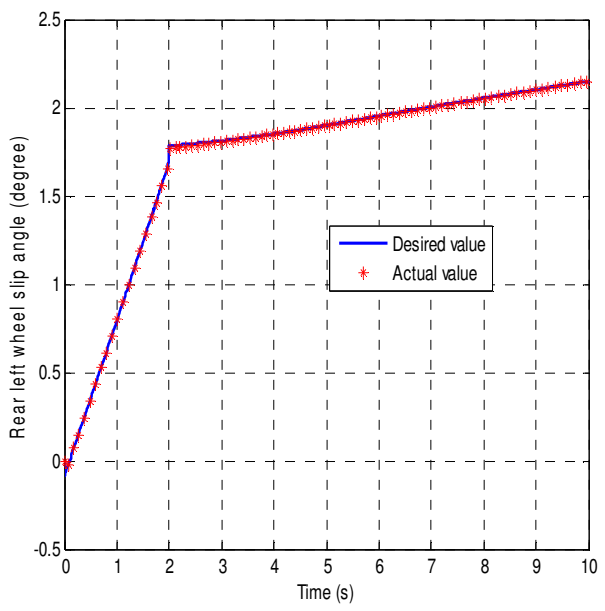

(c)

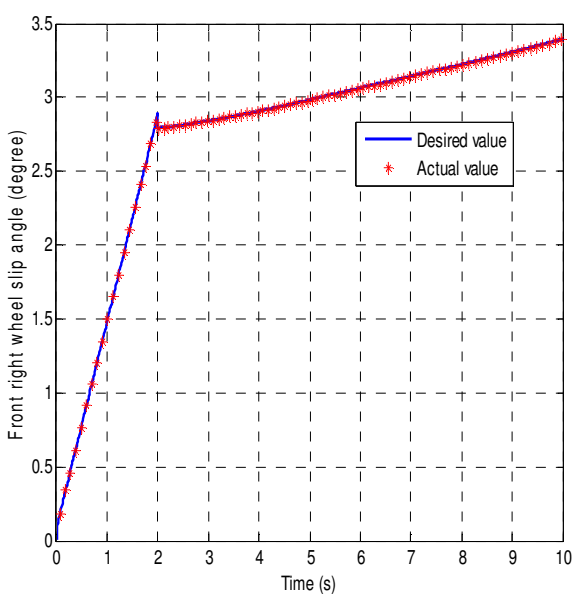

(b)

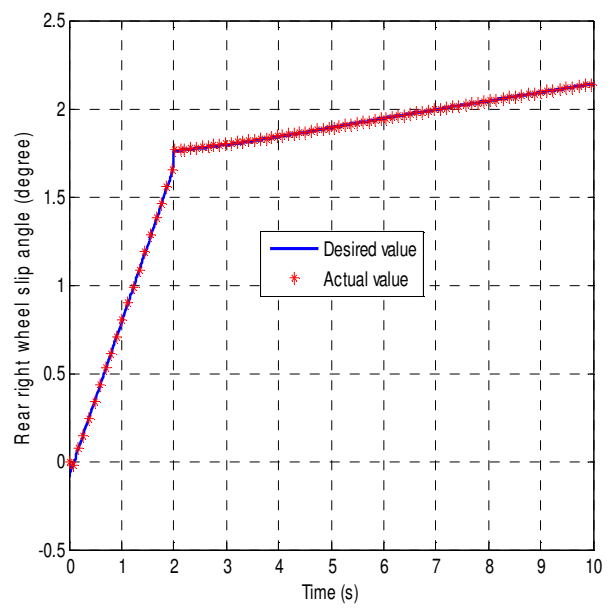

(d)

Figure 26. The individual wheel slip angle controlled by the non-linear method during the combined driving and steering motion: (a) front left wheel (b) front right wheel (c) rear left wheel (d) rear right wheel.

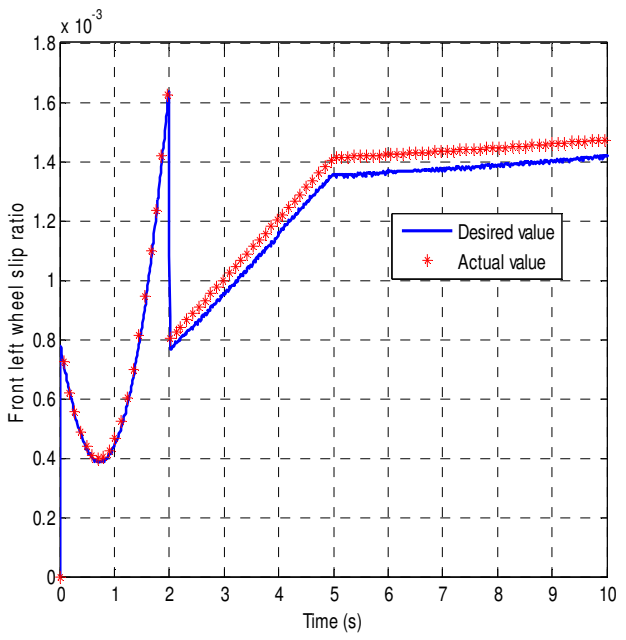

(a)

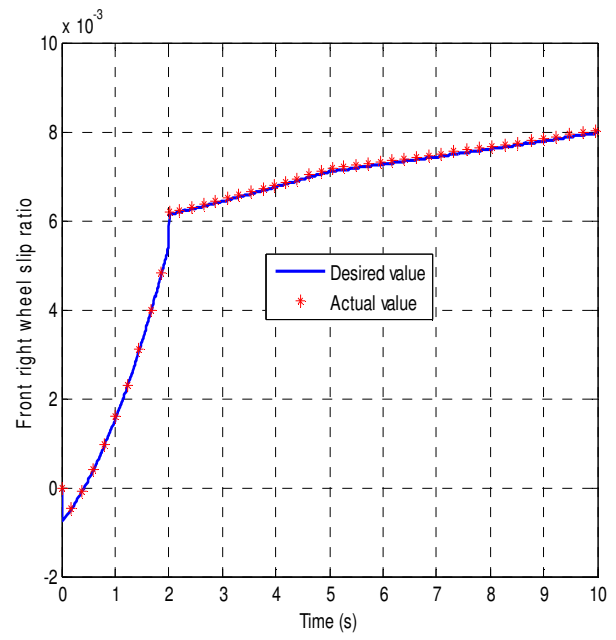

(b) 


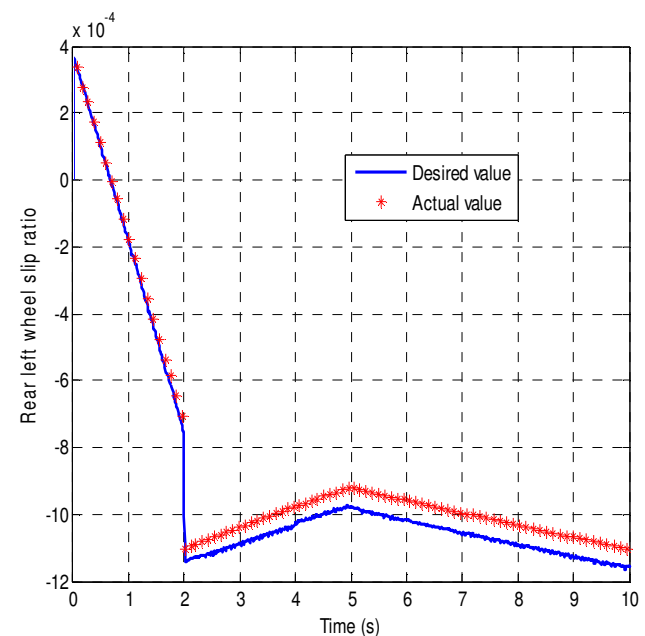

(c)

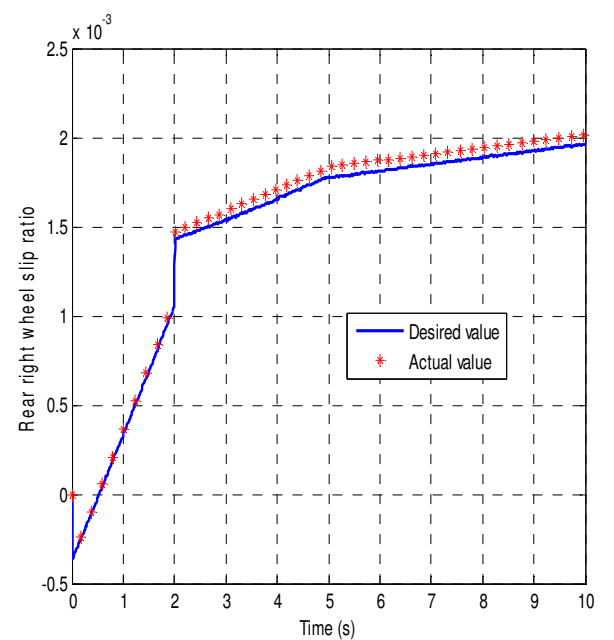

(d)

Figure 27. The individual wheel slip ratio of the vehicle controlled by the non-linear method during the combined driving and steering motion: (a) front left wheel (b) front right wheel (c) rear left wheel $(\mathrm{d})$ rear right wheel.

The split surface road condition can be referred to the split of road surface between front and rear parts of the vehicle [31] or the split of road surface between the left and right wheels of the vehicle [32]. To examine the simulation performance under the condition of the split of road surface between front and rear of the vehicle, the friction coefficient is assumed to be changed from 0.9 to 0.7 at 5 seconds in the third simulation. The simulation responses of yaw rate and body slip angle in Figures 28 and 29 prove that the desired vehicle dynamics performance can be well achieved. Alternatively, to evaluate the control performance under the condition of the split of road surface between the left and right wheels of the vehicle, the friction coefficient of the left wheel is assumed as 0.9 and the friction coefficient of the right wheel is 0.7. The simulation results in Figure 30 and 31 suggest that the proposed non-linear controller can achieve the good yaw rate and body slip angle responses, although the yaw rate response is a little compromised due to the split surface. 


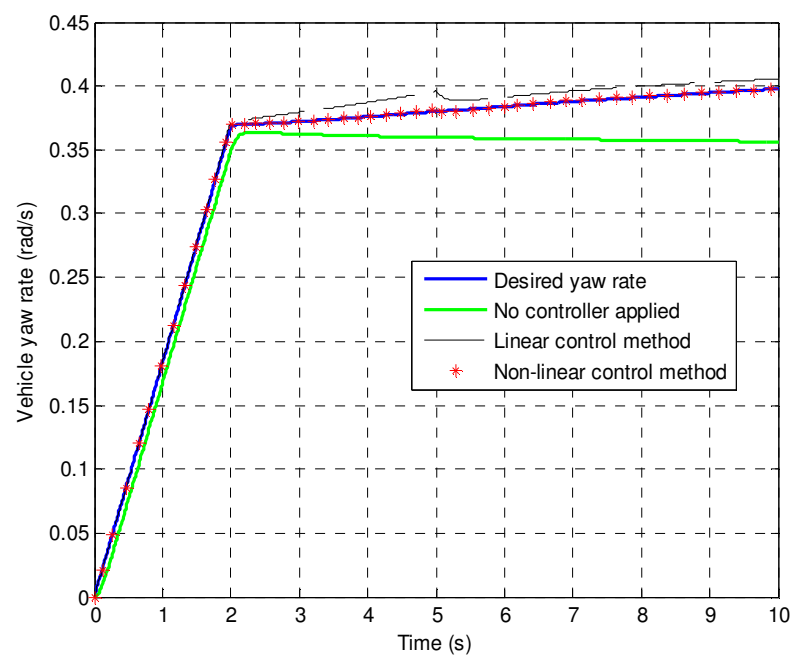

Figure 28. The vehicle yaw rate response during the combined driving and steering motion under split surface road condition - the split of road surface between front and rear of the vehicle.

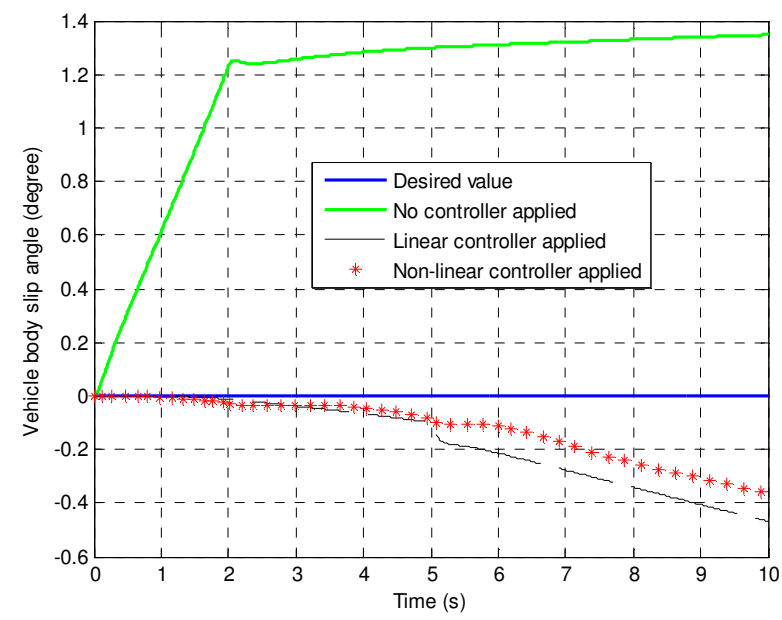

Figure 29. The vehicle body slip angle response during the combined driving and steering motion under split surface road condition - the split of road surface between front and rear of the vehicle. 


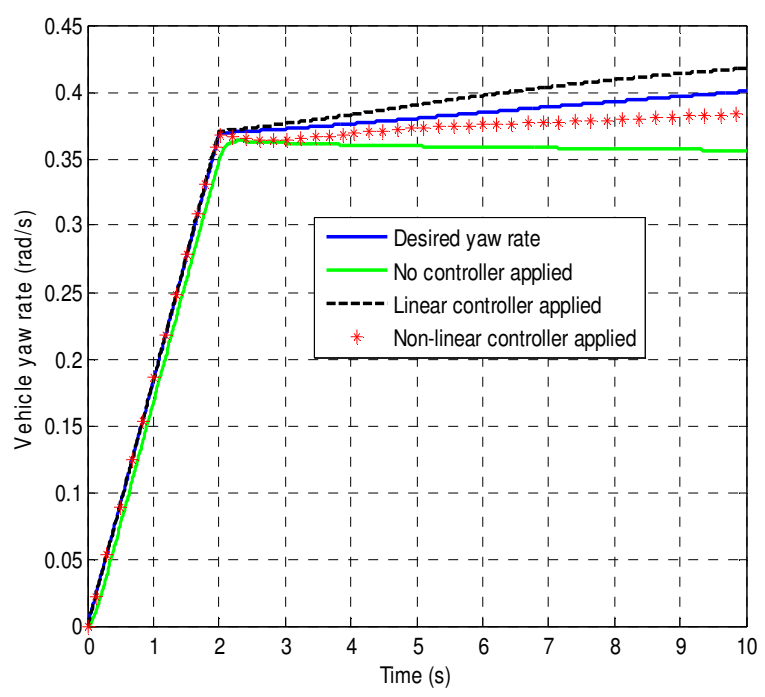

Figure 30. The vehicle yaw rate response during the combined driving and steering motion under split surface road condition - the split of road surface between left and right wheels.

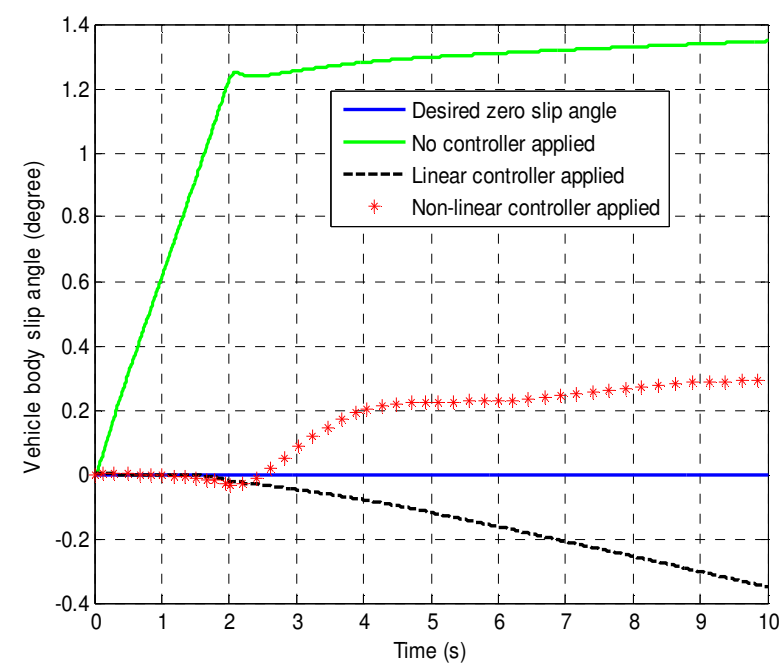

Figure 31. The vehicle body slip angle response during the combined driving and steering motion under split surface road condition - the split of road surface between left and right wheels.

The root mean square (RMS) errors of the yaw rate response and body slip angle response (compared with desired yaw rate and slip angle) of both linear and non-linear methods are summarised in Table 5 and Table 6. In Table 5, the linear method has worse yaw rate tracking performance compared with the no-controller-applied situation in most of the simulations. This is because in the linear method, the desired lateral tyre forces are achieved by linear mapping of the steering angles, and the distributed steering angles are different from the desired ones due to the non-linear tyre characteristics. Due to this error, the RMS yaw rate error of the linear method is relatively large. In the no-controller-applied situation, the 
required steering angles are directly applied to the two front wheels of the vehicle and consequently the RMS error is relatively small compared with the linear method. In the case of non-linear controller, the desired tyre forces can be achieved by taking into consideration the non-linear tyre characteristics and this results in a much better yaw rate tracking performance compared with the linear control and no-controller-applied situations. From Table 6, it can be seen that both linear and non-linear methods have good body slip angle control performance compared with the no-controller-applied situation. This proves that the desired body slip angle can be tracked well when the desired tyre forces are achieved using the non-linear method.

Table 5. The RMS errors of yaw rate by different methods.

\begin{tabular}{|c|c|c|c|}
\hline & No controller applied & $\begin{array}{c}\text { Linear distribution } \\
\text { method }\end{array}$ & $\begin{array}{c}\text { Non-linear } \\
\text { distribution method }\end{array}$ \\
\hline Simulation 1 & 0.0184 & 0.0598 & 0.0018 \\
\hline Simulation 2 & 0.0078 & 0.0107 & 0.0020 \\
\hline Simulation 3 & 0.0096 & 0.0196 & $8.1896 \times 10^{-4}$ \\
\hline $\begin{array}{c}\text { Simulation 3 } \\
\text { Split of road surface } \\
\text { between the front and } \\
\text { rear parts of vehicle }\end{array}$ & 0.0069 & 0.0084 & $6.2269 \times 10^{-4}$ \\
\hline $\begin{array}{c}\text { Simulation 3 } \\
\text { Split of road surface } \\
\text { between left and right } \\
\text { wheels }\end{array}$ & 0.0272 & 0.0164 & 0.0091 \\
\hline
\end{tabular}

Table 6. The RMS errors of body slip angle by different methods.

\begin{tabular}{|c|c|c|c|}
\hline & No controller applied & $\begin{array}{c}\text { Linear distribution } \\
\text { method }\end{array}$ & $\begin{array}{c}\text { Non-linear } \\
\text { distribution method }\end{array}$ \\
\hline Simulation 1 & 0.0102 & $8.3032 \times 10^{-4}$ & $3.4437 \times 10^{-4}$ \\
\hline Simulation 2 & 0.0230 & 0.0019 & 0.0032 \\
\hline Simulation 3 & 0.0211 & 0.0024 & 0.0027 \\
\hline $\begin{array}{c}\text { Simulation 3 } \\
\text { Split of the road surface } \\
\text { between front and rear } \\
\text { parts of vehicle }\end{array}$ & 0.0211 & 0.0037 & 0.0027 \\
\hline $\begin{array}{c}\text { Simulation 3 } \\
\text { Split of road surface } \\
\text { between left and right } \\
\text { wheels }\end{array}$ & 0.0211 & 0.0030 & 0.0033 \\
\hline
\end{tabular}




\section{CONCLUSION}

This study proposes a two-level tyre force distribution and control method for yaw rate and body slip angle control. The upper level controller obtains the desired lateral and longitudinal tyre force of each individual wheel according to the driver's virtual steering and virtual driving inputs. Then, the lower level controller maps the desired tyre forces into the individual steering actuator and driving actuator. Unlike the linear mapping used in the traditional method, this study develops the PI controller of the individual actuator. Specifically, when the desired individual tyre force is known, the desired longitudinal slip ratio and lateral slip angle can first be calculated by the inverse Dugoff tyre model. Then the PI controller is implemented to control the individual actuator according to the difference between the desired slip angle (slip ratio) and the actual one. The control gains of PI controllers are determined by a GA. The simulation results verify that:

1) In all the simulations of the J-turn, lane change and combined traction and J-turn manoeuvres, the non-linear method considers the non-linear tyre characteristic and consequently the controlled yaw rate and body slip angle track the desired values more accurately.

2) The RMS errors of the yaw rate and body slip angle responses in all the simulations also suggest that the non-linear method has good yaw rate and body slip angle tracking performance.

3) PI control gains can be determined offline in the preliminary simulations. During the actual vehicle motion, these PI control gains are already available for various vehicle velocity conditions. According to the velocity range of a particular vehicle, the corresponding group of PI control gains is selected. These PI control gains are robust in a simple J-turn motion, lane change motion and combined steering and driving motion (on the split surface road) within a certain range of vehicle velocity, as have been proven in the simulations. If there is a large change in vehicle velocity, the pre-determined PI control gains can be quickly switched.

4) The GA is proved to successfully determine a large number of control gains simultaneously at reasonable computation cost. Since the GA is the optimal search method in the area of artificial intelligence, it has a faster convergence rate and a lower computational cost than the conventional mathematical optimisation method.

5) The individual wheel slip ratio and slip angle PI controllers can successfully achieve the whole vehicle body slip angle and optimal yaw rate control. This suggests that when the desired slip ratio and slip angle of individual wheels are achieved by the lower level PI controllers, the desired individual tyre force, yaw rate and body slip angle in the upper controller can be achieved. In this way, the two-level control system proposed in this study can successfully achieve the desired control targets.

Individual tyre force distribution and control is an over-actuated control problem. To fully utilise the redundant actuators, in future, the fault tolerant control and energy efficiency 
control could also be included in the proposed distribution control method. The proposed control method will also need to be tested on a real electric vehicle with independent steering and driving to verify the simulation results.

\section{ACKNOWLEDGEMENTS:}

This research was supported under Australian Research Council's Discovery Projects funding scheme (project number DP140100303).

The authors wish to gratefully acknowledge the help of Dr. Madeleine Strong Cincotta in the final language editing of this paper.

\section{References}

[1] Johanson, T.A., and Fossen, T.I., "Control allocation - A survey", Automatica, vol.49, no.5, pp.1087-1103, 2013.

[2] Oppenheimer, M., Doman, D., and Bolender, M., Control allocation, in W. S. Levine, ed., 'The Control Handbook, Control System Applications, Second Edition', chapter 8.

[3] Fossen, T.I., and Johansen, T.A., 'A survey of control allocation methods for ships and underwater vehicles', in $14^{\text {th }}$ Mediterranean Conference on Control and automation, Ancona.

[4] Wang, J., and Longoria, R.G., 'Coordinated and reconfigurable vehicle dynamics control', IEEE Trans. Control Syst. Technol., vol.17, no.3, pp. 723-732, May 2009.

[5] Plumlee, J.H., Bevly, D.M., and Hodel, A.S., 'Control of a ground vehicle using quadratic programming based control allocation techniques', in Proc. 2004 Amer. Control Conf., 2004, pp. 4704-4709.

[6] Shuai, Z., Zhang, H., Wang, J., Li, J., and Ouyang, M., "Lateral motion control for fourwheel-independent-drive electric vehicles using optimal torque allocation and dynamic message priority scheduling", Control Engineering Practice 24, pp.55-66, 2014.

[7] Shuai, Z., Zhang, H., Wang, J., Li, J., and Ouyang, M., "Network control of vehicle lateral dynamics with control allocation and dynamic message priority assignment", ASME 2013 Dynamics Systems and Control Conference, Palo Alto, California, USA, October 21-23, Paper No. DSCC2013-3890, 2013.

[8] Chen, Y., and Wang, J., 'Design and experimental evaluations on energy efficient control allocation methods for overactuated electric vehicles: Longitudinal case', IEEE/ASME Transactions on Mechatronics, vol.19, no.2, 2014. 
[9] Gerard, M., Schutter B., and Verhaegen, M., 'A hybrid steepest descent method for constrained convex optimization’, Automatica, vol. 45, pp. 525-531, 2009.

[10] Tjønnås, J., and Johansen, T.A., 'Stabilization of automotive vehicle using active steering and adaptive brake control allocation', IEEE Transactions on Control Systems Technology, vol.18, no.3, 2010.

[11] Chen, Y., and Wang, J., "Design and experimental evaluations on energy efficient control allocation methods for overactuated electric vehicles: Longitudinal motion case", IEEE Transactions on Mechatronics, vol.19, no.2, pp.538-548, 2014.

[12] M. Demirci and M. Gokasan, "Adaptive optimal control allocation using Lagrangian neural networks for stability control of a 4WS-4WD electric vehicle", Transactions of the Institute of Measurement and Control, vol. 35, no.8, pp.1139-1151, 2013.

[13] Ando, N., and Fujimoto, H., "Yaw-rate control for electric vehicle with active front/rear steering and driving/braking force distribution of rear wheels," The $11^{\text {th }}$ IEEE International Workshop on Advanced Motion Control, pp.726-731, March 21-24, 2010, Nagaoka, Japan.

[14] Suzuki, Y., Kano, Y., and Abe, M., 'A study on tyre force distribution controls for full drive-by-wire electric vehicle', Vehicle System Dynamics, DOI:

10.1080/00423114.2014.894198.

[15] Vallada, E., and Ruiz, R., 'A genetic algorithm for the unrelated parallel machine scheduling problem with sequence dependent setup times', European Journal of Operational Research, vol.211, pp.612-622, 2011.

[16] Vidal, T., Crainic, T.G., Gendreau, M., Prins, C., 'A hybrid genetic algorithm with adaptive diversity management for a large class of vehicle routing problems with timewindows', Computers \& Operations Research, vol.40, pp.475-489, 2013.

[17] Roberge, V., Tarbouchi, M., and Labonté, G., 'Comparison of Parallel Genetic Algorithm and Particle Swarm Optimization for Real-Time UAV Path Planning', IEEE Transactions on Industrial Informatics, Vol. 9, No. 1, pp.132-141, 2013.

[18] Li, B.Y., Li, W.H., Kennedy, O., and Du, H.P., "The dynamics analysis of an omnidirectional vehicle," International Journal of Automotive Technology, vol.15, no.3, pp.387398, 2014.

[19] Boada, B., Boada, M. and Díaz, V., "Fuzzy-logic applied to yaw moment control for vehicle stability," Vehicle System Dynamics, vol.43, pp.753-770, 2005.

[20] Dugoff, H., Fancher, P.S. and Segel, L., "An analysis of tire traction properties and their influence on vehicle dynamic performance", SAE 700377, pp. 1219-1243, 1970.

[21] Lu, S-B, Lim, C.W., and He, Y-B, "Steering-based fault-tolerant control for the braking failures of an independent driving electric vehicle", Proc ImechE Part D: J Automobile Engineering, DOI: 10.1177/0954407014527740, 2014. 
[22] Wang, R., and Wang, J., "Tire-road friction coefficient and tire cornering stiffness estimation based on longitudinal tyre force difference generation", Control Engineering Practice, vol.21, no.1, pp.65-75, 2013.

[23] Zhao, Y., and Zhang, J., "Yaw stability control of a four-independent-wheel drive electric vehicle", Int. J. Electric and Hybrid Vehicles, vol.2, no.1, pp.64-76, 2009.

[24] Wang, J., Alexander, L., and Rajamani, R., "Friction estimation on high-way vehicles using longitudinal measurements", ASME J. Dyn. Syst.,Meas. Control, vol.126, no.2, pp.265275, 2004.

[25] Rajamani, R., Phanomchoeng,G., Piyabongkarn, D., and Lew, J.Y., "Algorithms for real-time estimation of individual wheel tire-road friction coefficients", IEEE/ASME Transactions on Mechatronics, vol.17, no.6, pp.1183-1195, 2012.

[26] Li, B., Du, H., and Li, W., "A novel cost effective method for vehicle tire-road friction coefficient estimation," in 2013 IEEE/ASME International Conference on Advanced Intelligent Mechatronics (AIM), pp.1528-1533, 2013.

[27] Li, B., Du, H., and Li, W., "Comparative study of vehicle tyre-road friction coefficient estimation with a novel cost-effective method", Vehicle System Dynamics, vol.52, no.8, pp.1066-1098, 2014.

[28] Li, L., Song, J., Kong, L., and Huang, Q., "Vehicle velocity estimation for real-time dynamic stability control”, International Journal of Automotive Technology, vol.10, no.6, pp.675-685, 2009.

[29] Imsland, L., Johansen, T.A., Fossen, T.I., Grip, H.F., Kalkkuhl, J.C., Suissa, A., "Vehicle velocity estimation using nonlinear observers", Automatica, vol.42, pp.2091-2103, 2006.

[30] Li, B., Du, H., and Li, W., "A novel method for side slip angle estimation of omnidirectional vehicles," SAE Int. J. Passeng. Cars - Electron. Electr. Syst., vol.7, no.2, 2014, doi:10.4271/2014-01-0303.

[31] Hori, Y., Toyoda, Y., and Tsuruoka, Y., "Traction control of electric vehicle: basic experimental results using the test EV 'UOT Electric March'”, IEEE Transactions on Industry Applications, vol.34, no.5, pp.1131-1138, 1998.

[32] Hebden, R.G., Edwards, C., and Spurgeon, S.K., "Automotive steering control in a split$\mu$ manoeuvre using an observer-based sliding mode controller," Vehicle System Dynamics, vol.41, no.3, pp.181-202, 2004. 